\title{
STS-133 Space Shuttle External Tank Intertank Stringer Crack Investigation Stress Analysis
}

\author{
Brian E. Steeve ${ }^{1}$ \\ National Aeronautics and Space Administration \\ Marshall Space Flight Center \\ Huntsville, AL 35812 \\ $53^{\text {rd }}$ AIAA/ASME/ASCE/AHS/ASC Structures, Structural Dynamics and Materials Conference \\ April 23-26, 2012 \\ Honolulu, Hawaii \\ Category: Structures
}

\section{Extended Abstract}

\section{Introduction}

The first attempt to launch the STS-133 Space Shuttle mission in the fall of 2010 was halted due to indications of a gaseous hydrogen leak at the External Tank ground umbilical carrier plate seal. Subsequent inspection of the external tank (figure 1) hardware and recorded video footage revealed that the foam insulation covering the forward end of the intertank near the liquid oxygen tank had cracked severely enough to have been cause for halting the launch attempt on its own (figure 2). An investigation into the cause of the insulation crack revealed that two adjacent hat-section sheet metal stringers (figure 3) had cracks up to nine inches long in the forward ends of the stringer flanges, or feet, near the fasteners that attach the stringer to the skin of the intertank (figure 4). A repair of those two stringers was implemented and the investigation effort widened to understand the root cause of the stringer cracks and to determine whether there was sufficient flight rationale to launch with the repairs and the other installed stringers.

\section{Stringer Stress Analysis}

As part of the investigation a stress analysis of the stringer hardware was initiated by the Marshall Space Flight Center to help understand the behavior of the stringers under pre-launch and flight conditions. The stress analysis consisted of a detailed solid finite element (FE) model of the stringer along with portions of the intertank and liquid oxygen (LOX) tank and associated fasteners (figure 5). This paper describes the model and the methodology used to determine how the stringers reacted during the filling of the cryogenic liquid oxygen tank and during ascent. Results are presented for the nominal baseline configuration as well as potential off-nominal assembly conditions and a reinforced configuration.

Baseline results show that as the liquid oxygen level passes the intertank-to-LOX tank interface thermal shrinkage causes the forward end of the intertank to radially contract and force the ends of the stringers to bend inward. This bending load is transmitted to the stringer through the fasteners that attach the feet of the stringer to the intertank skin and forward chord. This localized fastener loading induces local bending stress in the stringer consistent with the location 
of the cracks observed on the STS-133 tank (figure 6). The amount and distribution of this localized bending around the fastener locations is found to be very dependent upon the amount of circumferential rotational restraint encountered by the intertank forward flange.

\section{Assembly Stress Studies}

Early in the investigation it was suspected that assembly stress was a contributing factor for the observed cracks. There were a few instances of stringers cracking during manufacturing and there existed the possibility for stresses to develop based on the dimensional tolerances and sequence of the assembly process. This paper describes how the FE model was used to investigate potential hardware conditions that might introduce assembly stress.

Results show that certain allowable stringer-to-skin gaps are benign, while other noncontrolled dimensional conditions could introduce significant stress. Since the actual assembly conditions were not recorded, and the assembly stress level could not readily be measured, the model cannot be used with confidence to estimate a credible level of assembly stress that could exist in a given stringer installation.

\section{Model Correlation with Tanking Test}

A major event in the stringer crack investigation was a tanking test. In this test the liquid hydrogen and oxygen tanks were filled in the same manner as during an actual launch attempt. The tanks were allowed to reach thermal equilibrium and then were drained. Intertank temperatures were measured during the test, which in turn were used to calibrate the thermal models used to provide the temperature profile inputs for the stress analysis FE model. The test also included optical measurements of the displacement of the outer surface of the forward end of the intertank insulation. The correlation presented in this paper shows that the circumferential rotation of the intertank forward flange calculated from the measured displacement matches the predictions from the FE model.

\section{Radius Block Reinforcement Assessment}

Following the tanking test an x-ray inspection of the forward ends of all accessible stringers was performed which revealed that three additional stringers were also cracked. This finding, along with other information discovered during the investigation regarding the pedigree of the stringers, pointed to a potential issue with the material behavior of two stringer manufacturing lots that were used for the STS-133 External Tank. Thus it was concluded that stringer cracking was a potential issue for many of the other stringers installed on the tank. The External Tank program then decided to proactively reinforce all forward ends of the stringer feet. This involved installing a thick backer plate, referred to as a radius block, to both feet of every accessible stringer from the second to seventh fastener from the forward end (figure 7).

This paper describes how the stringer stress analysis FE model was updated and used to quantify the benefit of adding the radius blocks. Results are compared to the baseline FE model without the radius blocks, and relative strength factors are determined for the critical areas. One such critical area is the region of the stringer around the first fastener, which is the highest stressed region in the baseline FE model and was not covered by the radius block modification. The results show that the stresses in this location are also reduced by the radius block. This 
paper also shows that the analytical strength factor increase computed using the FE model results are consistent with the results from structural testing that was performed to demonstrate the relative strength capability of a stringer with and without radius blocks.

\section{Conclusion}

The STS-133 stringer crack investigation concluded that there were two primary factors which likely contributed to the observed stringer cracks; 1) two manufacturing lots were produced with low material toughness, and 2) considerable assembly stress levels were likely present. While the FE model was able to assess the relative severity of some assembly conditions, it was not possible to credibly estimate the assembly stress level for the stringers on the intertank. However, the FE model was very beneficial in understanding the loading experienced by the stringer during tanking and flight and how the stringer behaved under those loads. In addition, when radius blocks were added, the FE model provided a quantitative estimate of the relative strength improvement of the reinforcement. This helped to develop the flight rationale needed to show the tank had adequate capability.

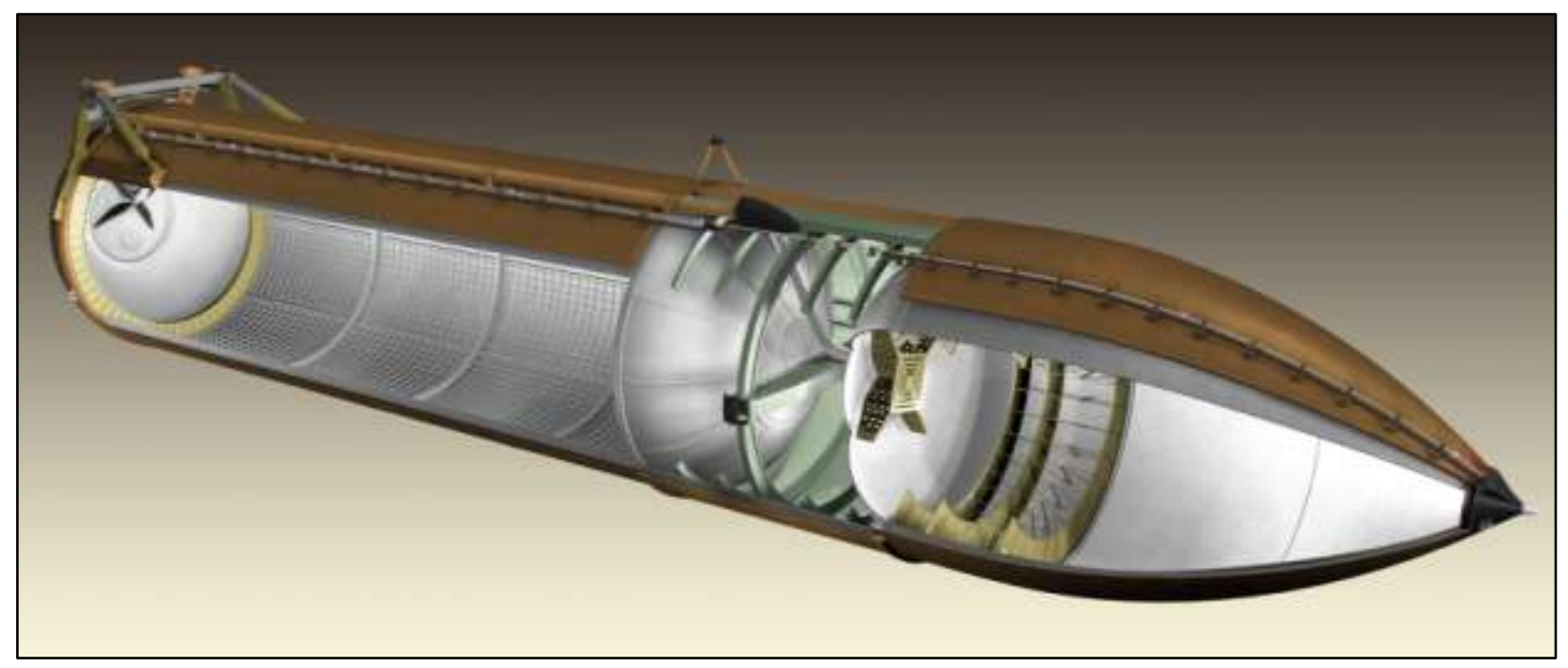

Figure 1 - Space Shuttle External Tank 


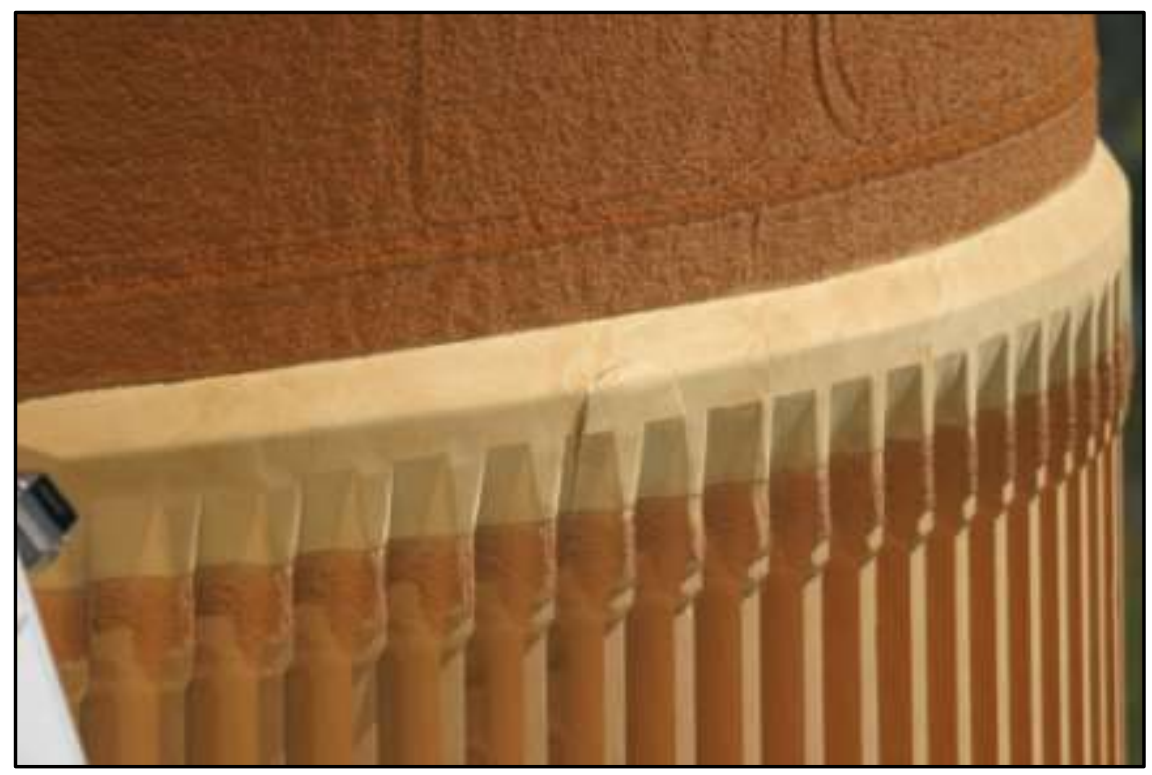

Figure 2 - LOX Tank to Forward End of Intertank Region Showing Crack in Foam Insulation

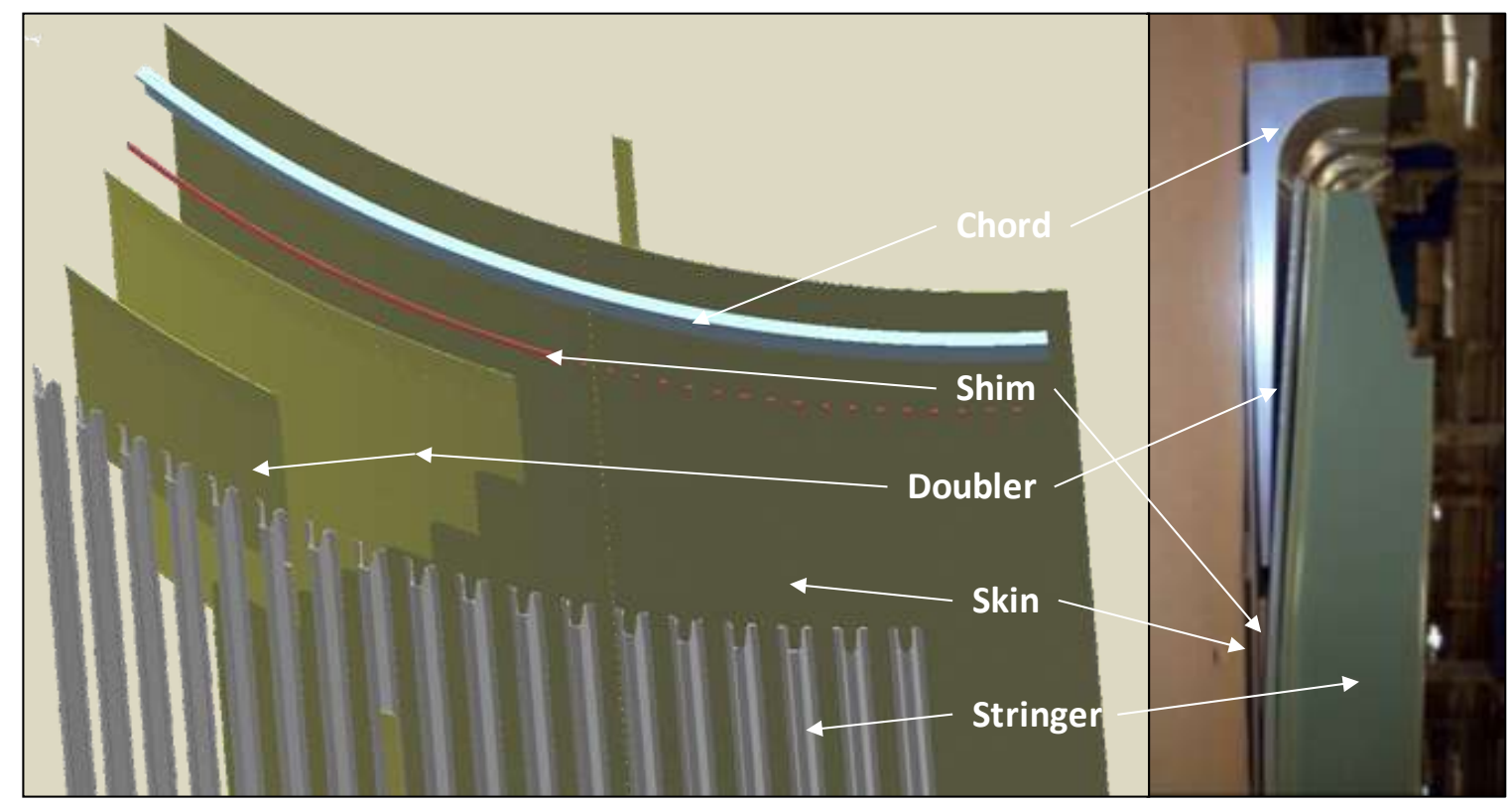

Figure 3 - Intertank Skin/Stringer Panel Configuration 


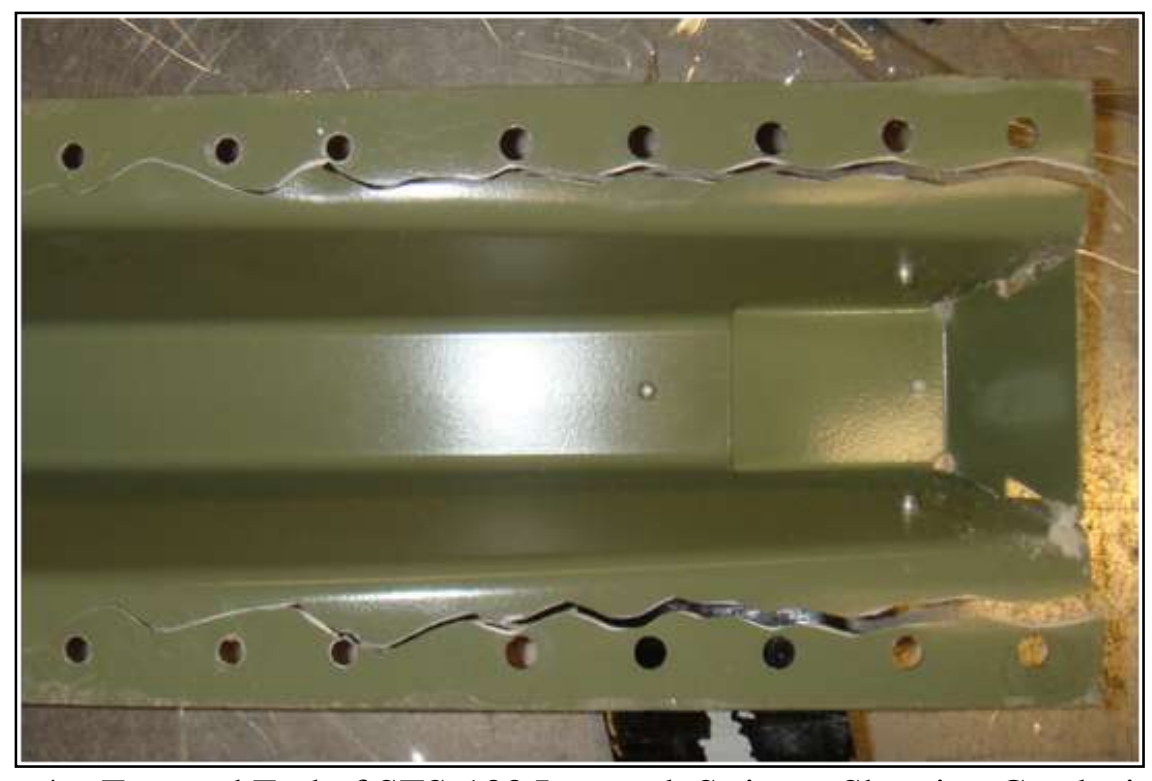

Figure 4 - Forward End of STS-133 Intertank Stringer Showing Cracks in Feet

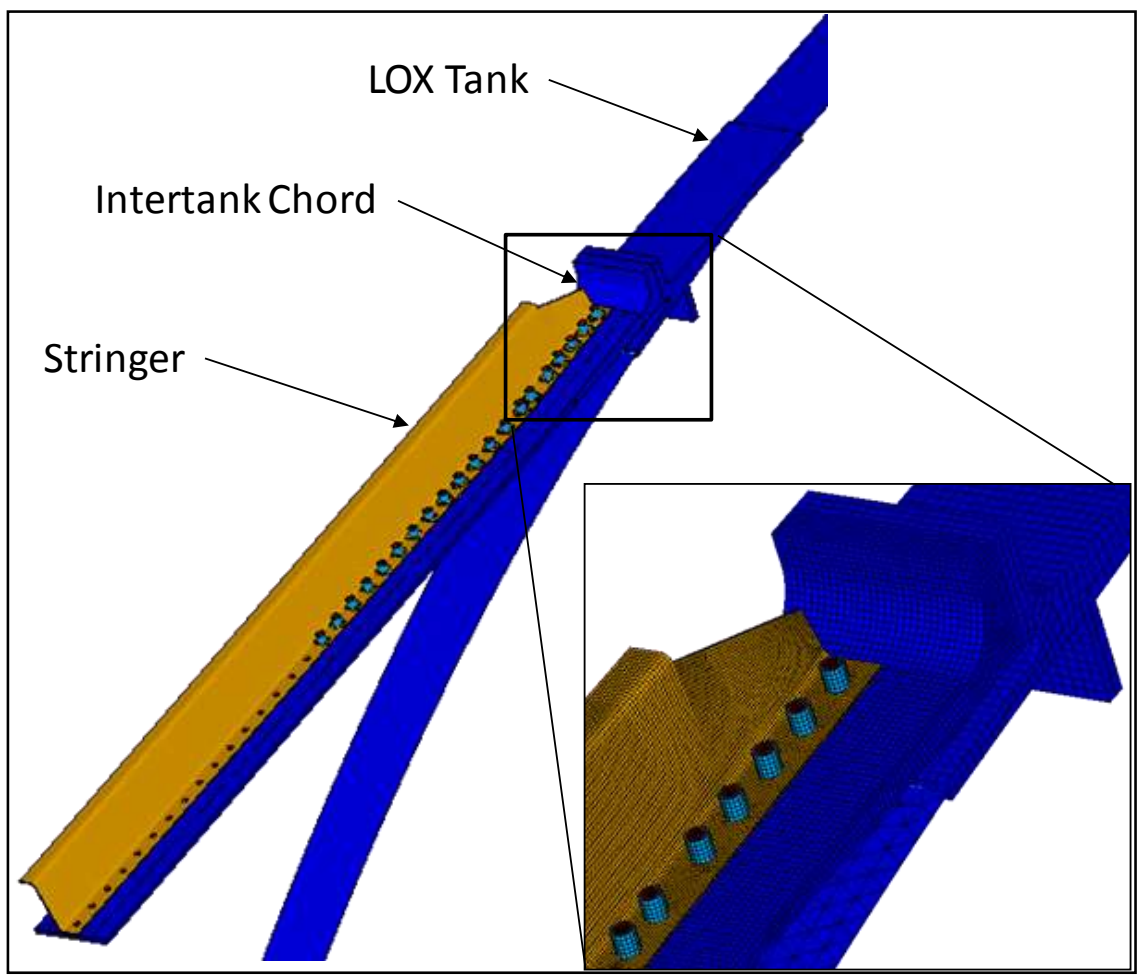

Figure 5 - Finite Element Model 


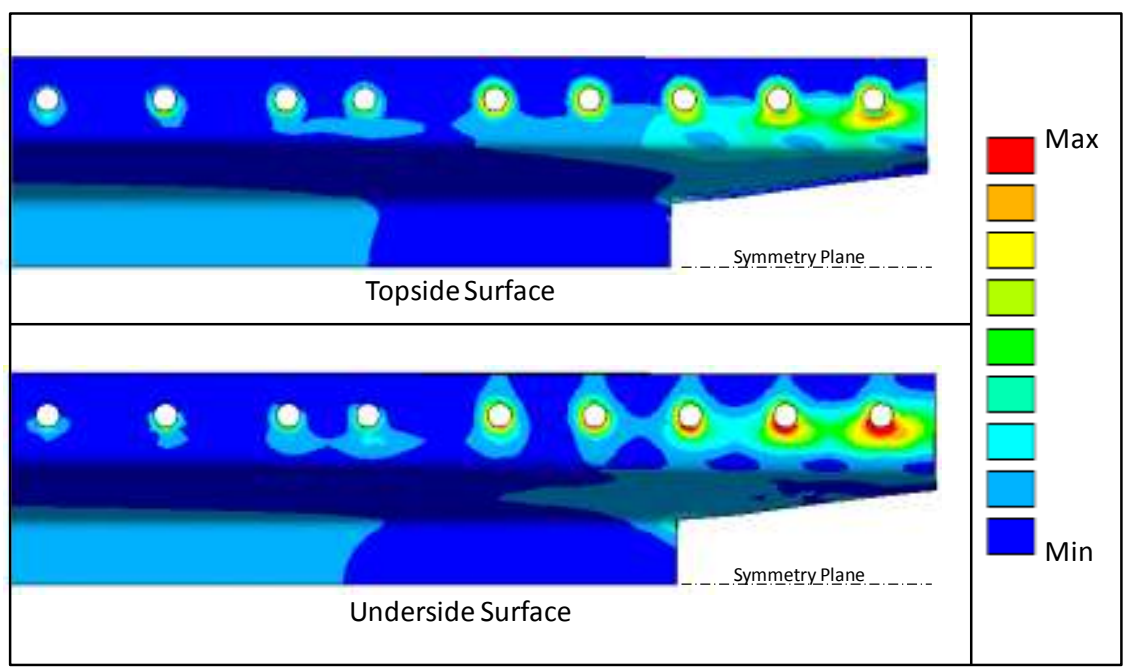

Figure 6 -High Stress Region around Forward Stringer Fastener Locations for Peak Tanking Transient Loading Condition

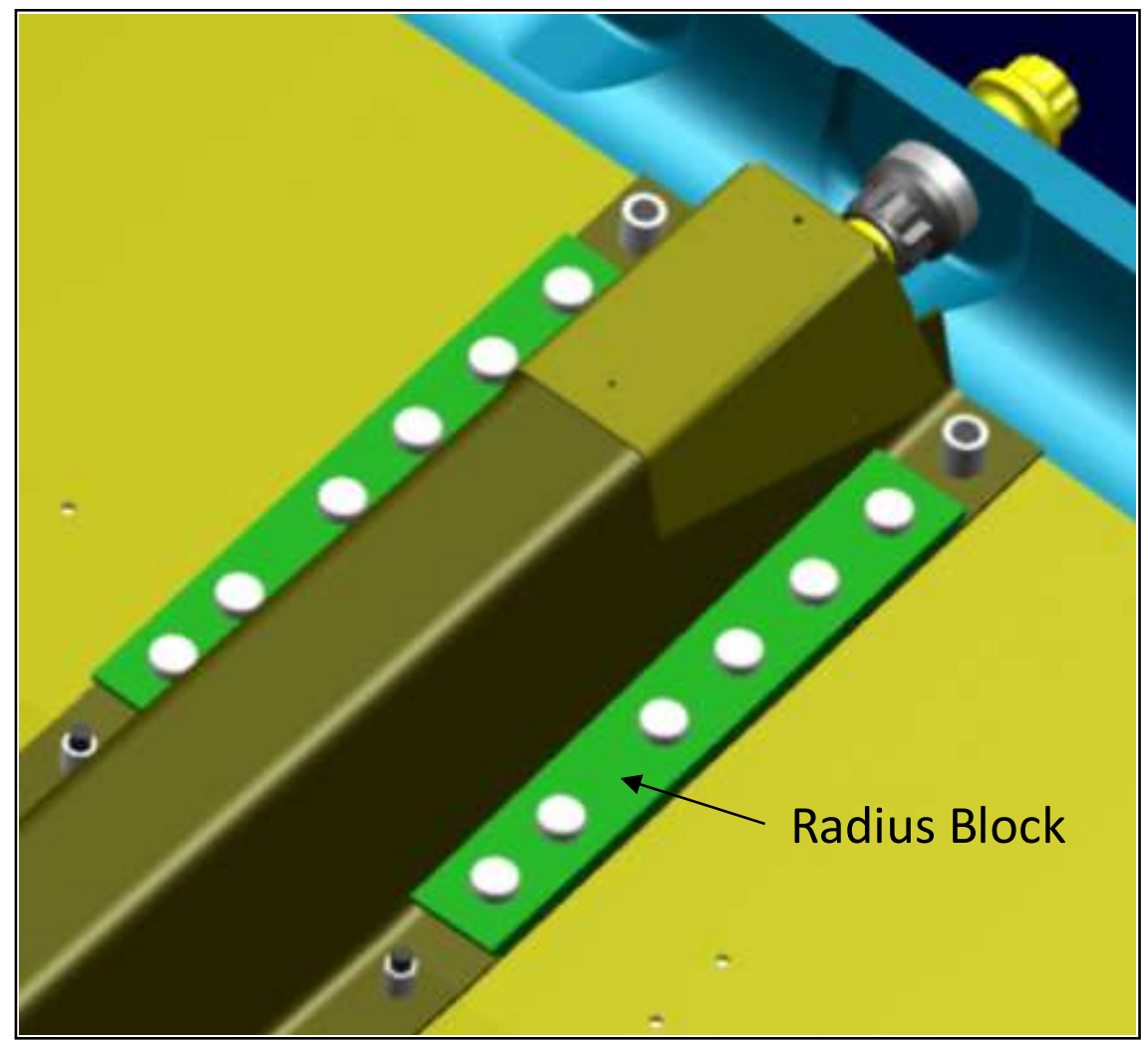

Figure 7 - Radius Block Modification 


\title{
STS-133 Space Shuttle External Tank Intertank Stringer Crack Investigation Stress Analysis
}

\author{
Brian E. Steeve ${ }^{1}$ \\ NASA George C. Marshall Space Flight Center, Huntsville, AL 35812
}

\begin{abstract}
The structural failure of five hat-section stringers on the intertank of the Space Shuttle STS133 External Tank prompted an investigation into the cause and the implementation of a repair. A detailed stress analysis of the failed hardware was performed by the Marshall Space Flight Center to help understand both the cause of the cracking and the effectiveness of the repair. The analysis showed how the stringers behaved as the External Tank is filled with cryogenic propellants. Assembly conditions that were considered potential contributors to the cause of the failure, due to induced assembly stress, were evaluated. The repair that was installed and flown was analyzed and shown to be effective in reducing the stress level in the stringer which contributed to the confidence in its performance. Results from the analysis were shown to be comparable with tanking test deformations and sub-component structural strength test results.
\end{abstract}

\section{Introduction}

The first attempt to launch the STS-133 Space Shuttle mission in the fall of 2010 was halted due to indications of a gaseous hydrogen leak at the External Tank ground umbilical carrier plate seal. Subsequent inspection of the external tank hardware and recorded video footage revealed that the foam insulation covering the forward end of the intertank near the liquid oxygen tank had cracked severely enough to have been cause for halting the launch attempt on its own (Figure 1). An investigation into the cause of the insulation crack revealed that two adjacent hat-section sheet metal stringers had cracks up to nine inches long in the forward ends of the stringer flanges, or feet, near the fasteners that attach the stringer to the skin of the intertank (Figure 2). A repair of those two stringers was implemented, and the investigation effort widened to understand the root cause of the stringer cracks and to determine whether there was sufficient flight rationale to launch with the repairs and the other installed stringers. As part of the investigation, a stress analysis of the stringer hardware was initiated by the Marshall Space Flight Center.

The stringer stress analysis was performed to help understand the behavior of the intertank stringers under prelaunch and flight conditions. The analysis focused on the forward end of a single stringer and how loads and stresses developed as the liquid oxygen (LOX) tank was filled on the launch pad and as it experienced flight design loads. The analysis was first used to look at a baseline nominal configuration. As the investigation proceeded, the analysis was also used to investigate off-nominal assembly conditions that were believed to be potential contributors to the stringer cracking, and it was further used to assess the repair method that was implemented on the tank. Testing that occurred on the actual flight tank and on subcomponent structural test articles produced results that compared favorably with the analysis results.

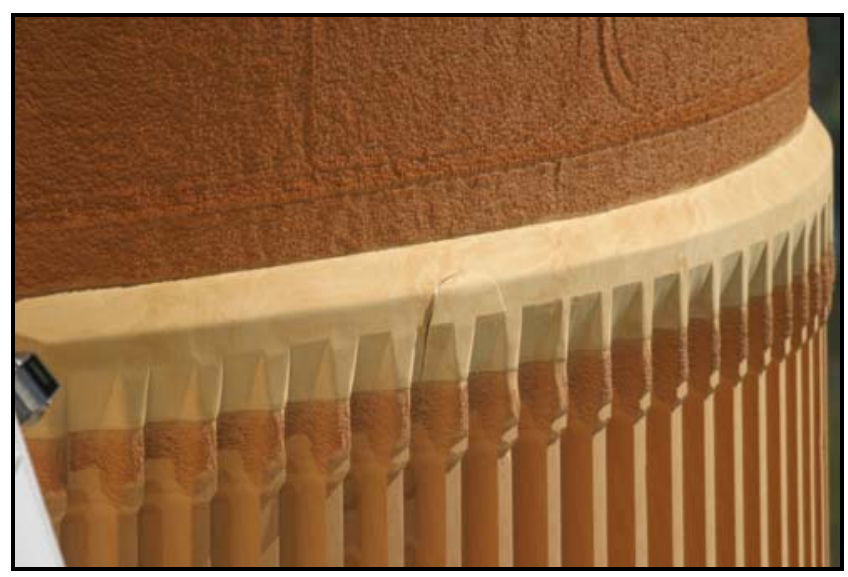

Figure 1. LOX tank to forward end of intertank region showing crack in foam insulation.

1 Aerospace Engineer, Structural Design and Analysis Division, Mail Stop EV31 


\section{Intertank Hardware and Loading}

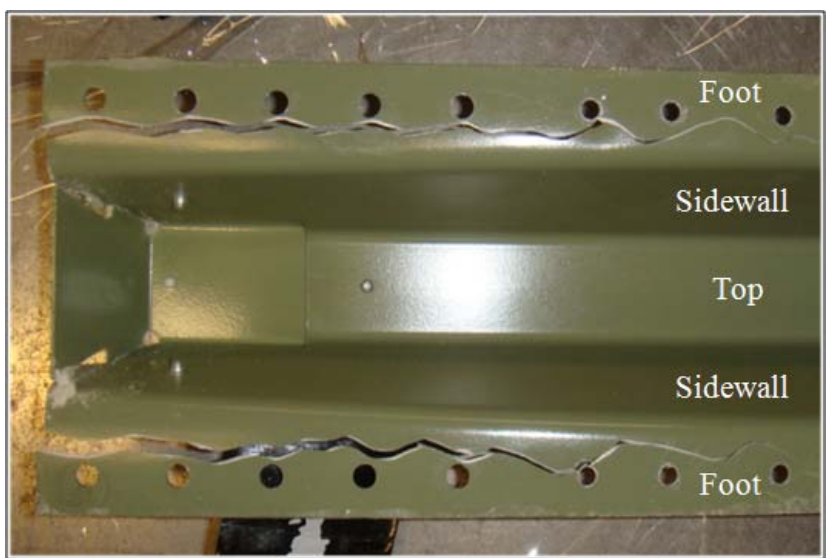

Figure 2. Forward end of STS-133 intertank stringer showing cracks in feet.

The External Tank intertank structure connects the liquid hydrogen (LH2) tank to the LOX tank and provides the thrust attach points for the two solid rocket boosters (SRB) (Figure 3). The intertank shell is primarily constructed with skin-stringer panels consisting of hat-section stringers fastened to a skin, which is reinforced with doubler skins in some regions (Figure 4). Integrally machined panels form the shell at the SRB attach points. The shell is reinforced with five internal ring frames, and a forward and aft chord are used as interfacing rings to bolt to the tank at each end.

The intertank experiences vehicle body loads sitting on the launch pad and during flight. On the pad, the vehicle load is primarily due to the weight of LOX tank, empty or full, which is reacted out at the SRB attach points. During flight the vehicle loads increase under flight accelerations. Another source of loading is due to thermal gradients, with the most significant occurring during the LOX tank fill before launch. This is the loading that caused the STS-133 stringers to crack. The metallic tank shrinks as it is filled with cryogenic LOX. When the LOX level passes the LOX tank yring, which interfaces with the intertank, the heavier section of the y-ring rapidly cools and shrinks, pulling the relatively warm intertank chord radially inward. The forward end of the intertank, including the stringers, is bent to follow the chord.

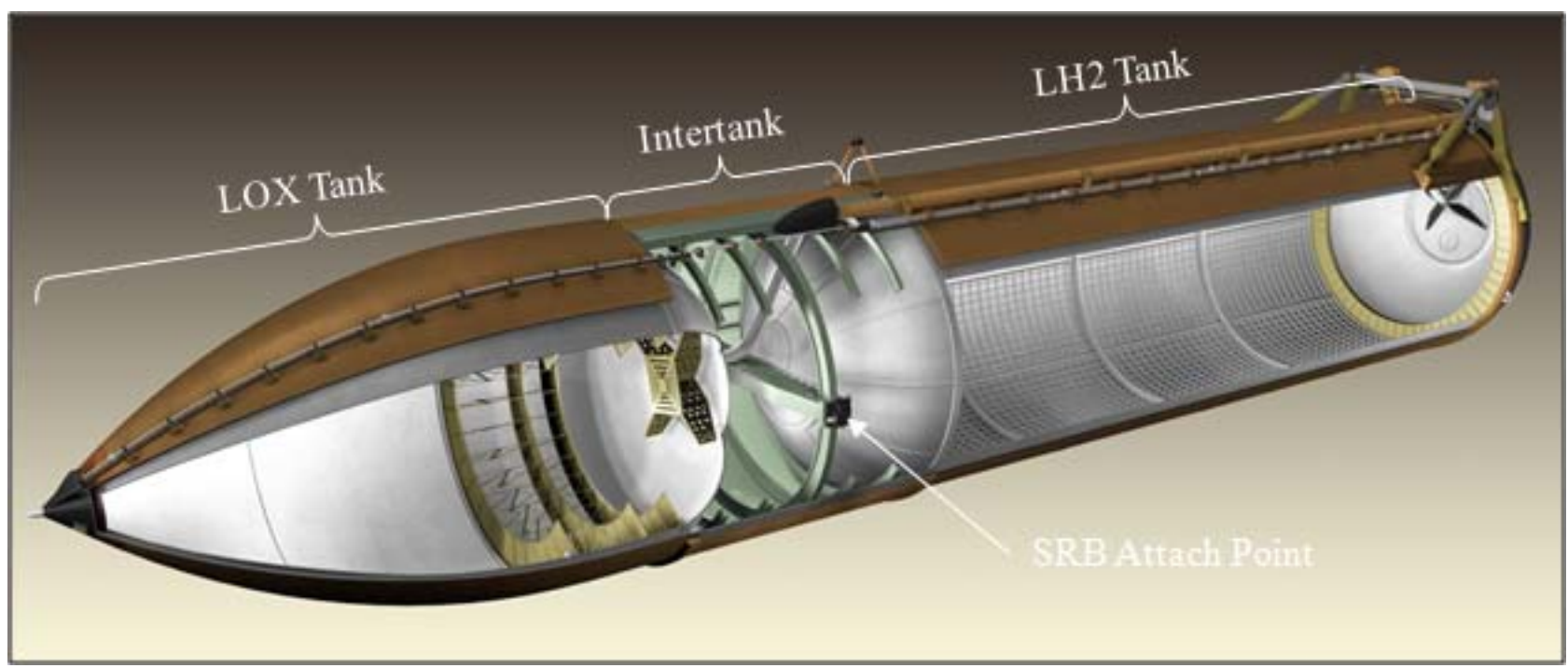

Figure 3. Space Shuttle External Tank. 


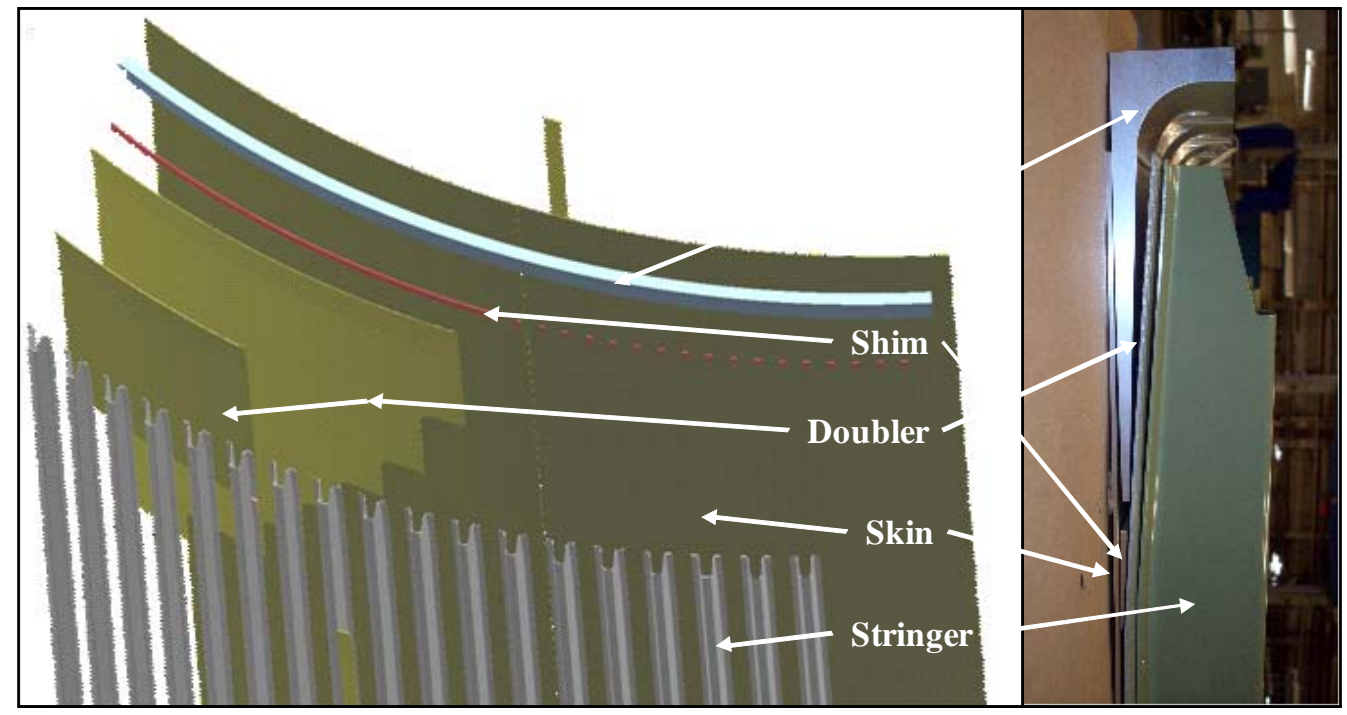

Figure 4. Intertank skin/stringer panel configuration.

\section{Stress Analysis Methodology}

The STS-133 stringer stress analysis was performed using a finite element (FE) model built and solved using the ANSYS Mechanical FE software program. Over the three month long investigation the model evolved to include more capability and fidelity. Initially the model consisted only of the forward end of the intertank. It was readily apparent from this initial model that the results were sensitive to the boundary conditions at the intertank chord flange. Portions of the LOX tank were then added to the model to move the boundary conditions away from the stringer region of interest. The final model consisted of a detailed solid FE model of a single stringer along with portions of the intertank and LOX tank (Figure 5). The model included a 44 inch length of a stringer in the axial direction, which is nearly the length between the forward end of the intertank and the first intertank ring frame. Approximately 40 inches of the LOX tank forward of the intertank was included along with the LOX tank aft dome. In the circumferential direction, the model took advantage of symmetry and only included one half of a stringer, extending from a stringer mid-plane to a plane halfway to the adjacent stringer.

The geometry of the stringer was fully captured including the fastener holes. Three eight-node solid elements were used through the thickness of the stringer sheet metal. The geometry of the skin, skin doublers, and chord was simplified by not including fastener holes and modeling them with a continuous finite element mesh. The interface between the stringer and skin included surface-tosurface contact with a coefficient of friction of 0.5. The fasteners that attach the stringer to the skin/chord were included in the model using beam elements. The ends of the fastener beam elements were constrained to the stringer and skin by coupling the degrees of freedom together. Linear elastic properties were used for all materials in the model. The sheet metal end-cap that covers the opening at the forward end of the stringer was not included in the model.

Symmetry boundary conditions were applied to both of the circumferential symmetry planes. The aft end was fixed in the axial direction. The forward end of the model was fixed in rotation about the circumferential direction. Vehicle loads were applied as an axial force to the forward end of the model. Thermal gradients were determined by a separate thermal analysis. The gradients were applied to the stress analysis model by specifying temperatures from the thermal analysis

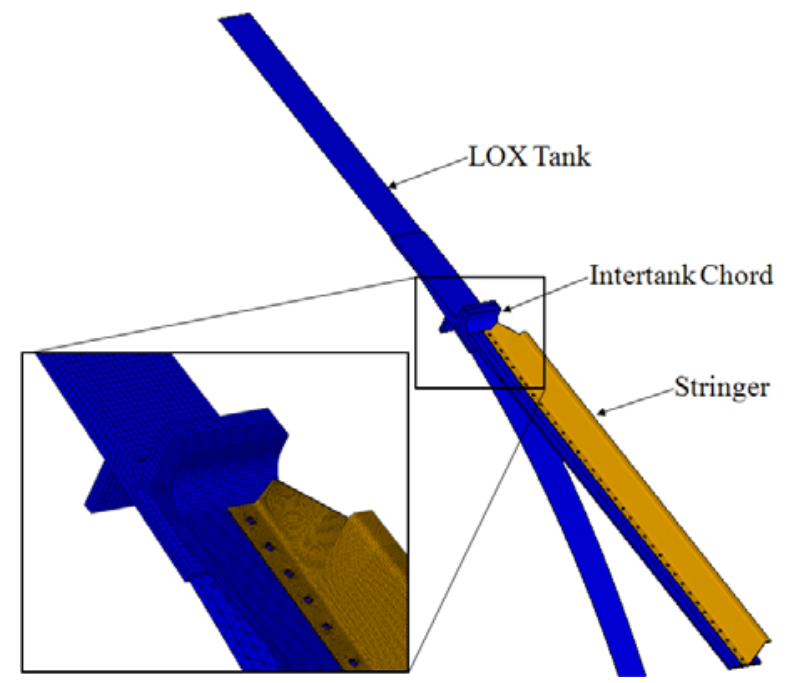

Figure 5. Finite element model. 
results at specific points for a given time and then performing a thermal solution with conduction and adiabatic boundary conditions to get temperatures throughout the model. The stress analysis read in the temperatures from the thermal solution.

\section{Baseline Results}

The baseline analysis consisted of nominal stringer geometry and dimensions. The load cases considered were the on-pad chill-down and ascent. The chill-down loads included the thermal gradient at various times during the chill-down transient (Figure 6) along with the corresponding vehicle axial load at that time. The vehicle axial load varied as a function of azimuth as determined from a previous analysis, so the applied load was chosen to represent a particular location around the tank. The ascent case included the maximum vehicle flight design load with the steady state thermal gradient for a full LOX tank.

The force imparted to the stringer was

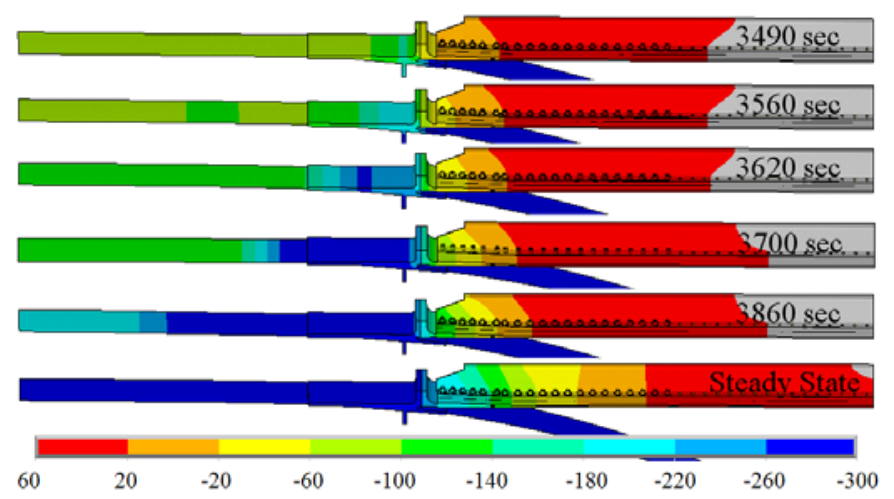

Figure 6. Chill-down transient temperature profiles $\left({ }^{\circ} \mathrm{F}\right)$. monitored in the analysis by extracting the force in the sidewall of the stringer at each fastener location. This was accomplished by summing the nodal forces at a plane just above the stringer sidewall to foot radius over a length associated with each fastener. Figure 7 plots the stringer force along the length of the stringer for various chill-down transient times and ascent.

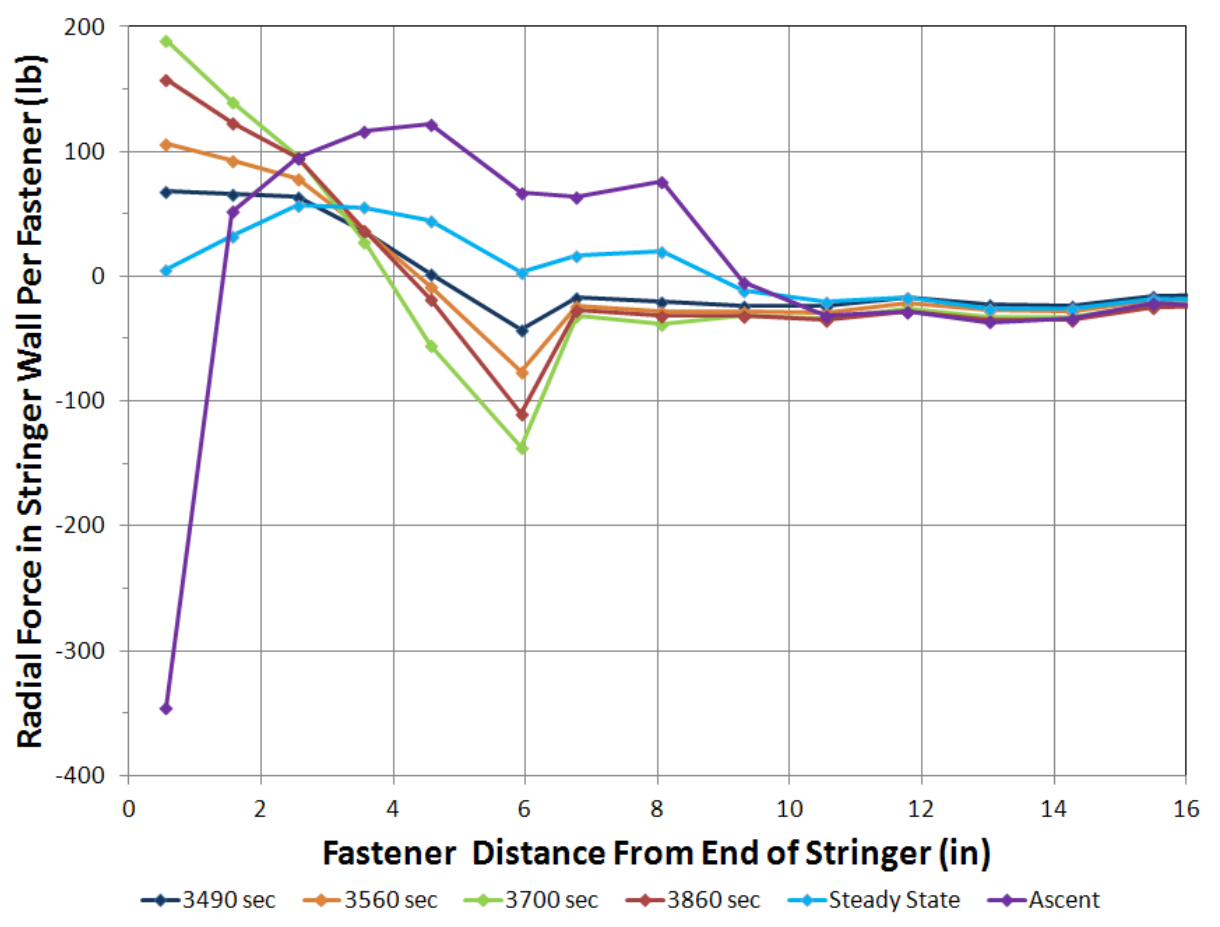

Figure 7. Stringer sidewall force during chill-down transient.

The chill-down loading was seen to introduce a radial inward pull force at the first four stringer fastener locations, which was reacted by a radial outward push force over the next few aft fastener locations. The loading is somewhat reversed in the ascent loading case. A compressive radial outward force is exerted on the tip of the stringer and a tensile inward pull force is exerted over the next seven fasteners. 
The pull force exerted through the forward fasteners causes significant bending to develop in the sheet metal of the stringer feet as illustrated in Figure 8.

Figure 9 shows the high stress regions around the forward fastener holes. Since the analysis material properties are elastic, the stress magnitude is above the actual yield stress of the material. In reality, yielding of the material would be expected to occur locally around the fastener heads.

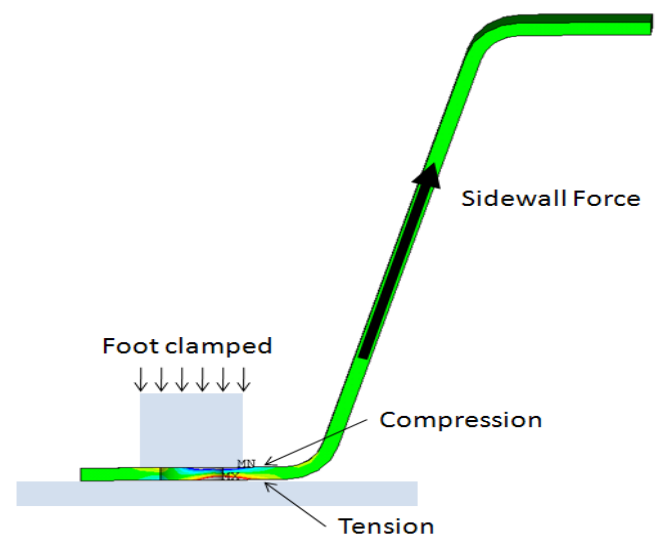

Figure 8. Development of bending stress in stringer foot at fasteners.

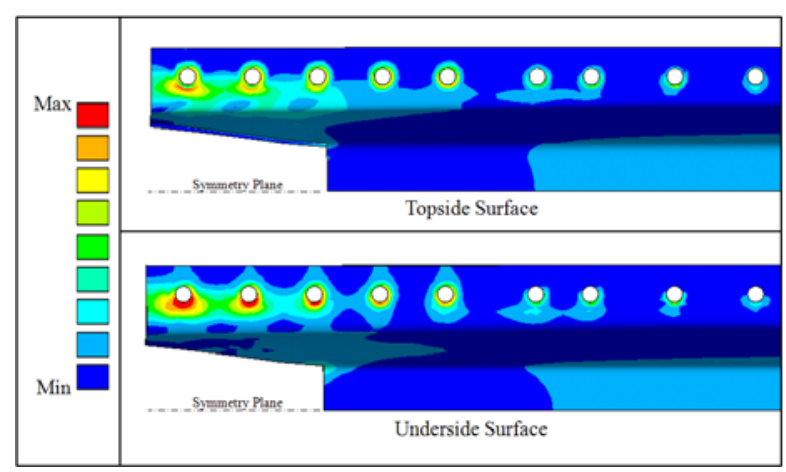

Figure 9. High stress region around forward stringer fastener locations for peak tanking transient loading condition.

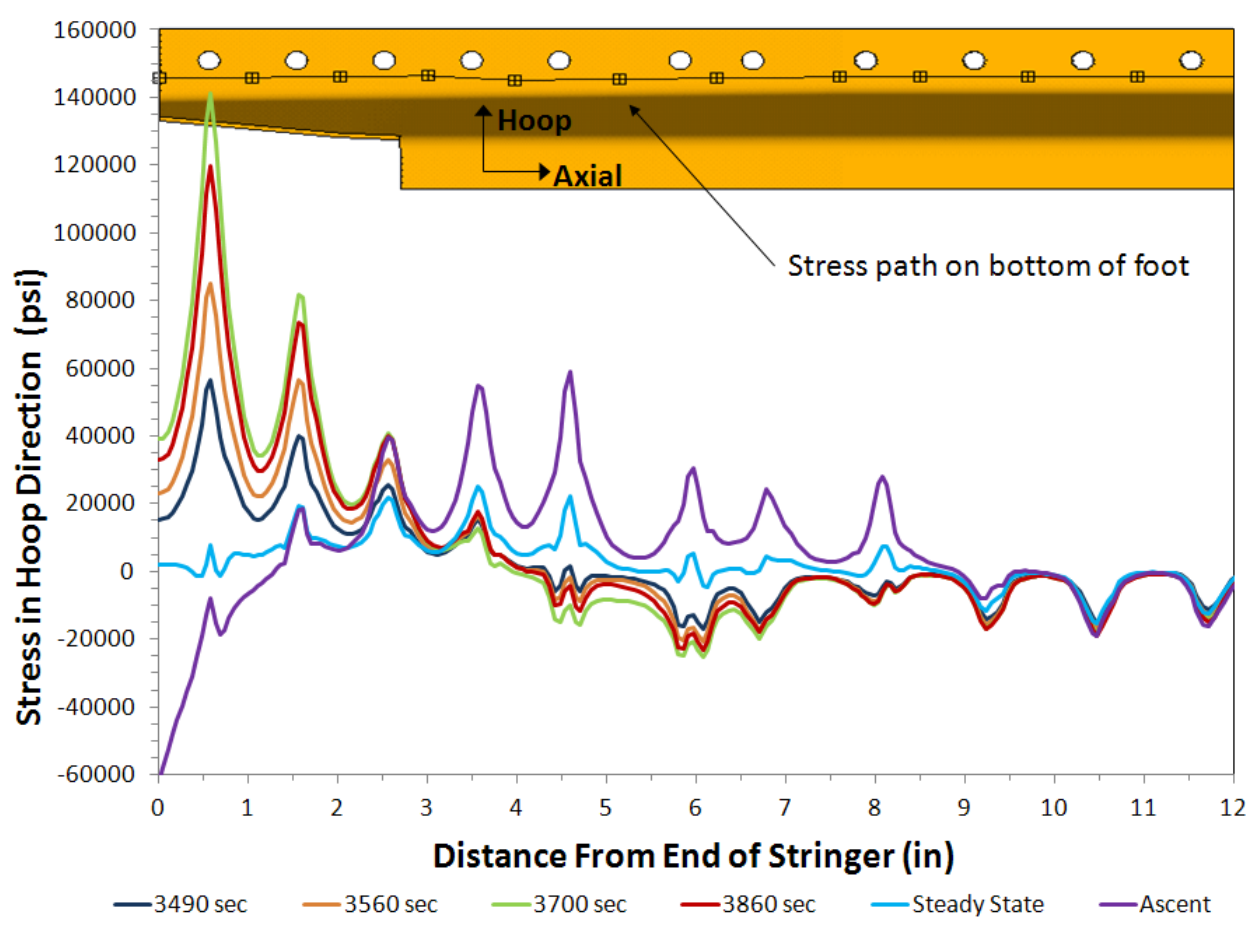

Figure 10. Stringer stress along path on bottom side of foot.

The stress in the foot of the stringer was further monitored in the analysis by plotting the stress along a path on the bottom of the stringer foot just inboard of the fastener hole. Figure 10 plots the stringer stress along this path for 
various chill-down transient times and ascent. The peak stresses around the first three fastener holes are prominent, while the stress level at the fourth fastener and beyond is relatively benign. The ascent load case is characterized by low sidewall force and foot stress in the first two fasteners but modestly increased load and stress around the fourth and fifth fastener region.

The chill-down transient time that produces the peak stringer force and stress is 3700 seconds, which corresponds to when the LOX level covers the LOX tank y-ring. After that time the intertank itself cools down, which causes the chord and skin to shrink in radially, thereby reducing the stringer bending severity.

\section{V.Model Validation}

The results from the stress analysis model were compared to the results from two tests. The first test was a tanking test that occurred during the middle of the investigation. The other was a series of sub-component structural tests that occurred during most of the investigation.

\section{A. Tanking Test Correlation}

The tanking test was a major event in the stringer crack investigation. In this test the STS-133 liquid hydrogen and oxygen tanks were filled in the same manner as during an actual launch attempt. The tanks were allowed to reach thermal equilibrium and then were drained. Intertank temperatures were measured during the test, which in turn were used to calibrate the thermal models used to provide the temperature profile inputs for the stress analysis FE model. The test also included optical measurements of the displacement of the outer surface of the forward end of the intertank insulation. Through data reduction of the measured out-of-plane displacements, the rotation of the intertank chord flange was calculated throughout the chill-down transient ${ }^{1}$. Figure 11 and Figure 12 plot the flange displacement and rotation, respectively, as a function of time. The displacement and rotation of the flange as predicted by the stress analysis is also plotted at the various times considered. The agreement between the measured and predicted data is reasonably good.

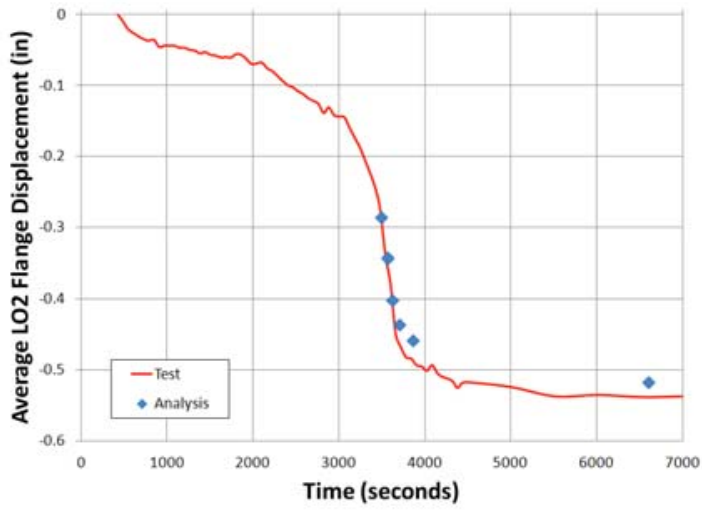

Figure 11. Tanking test average flange displacement

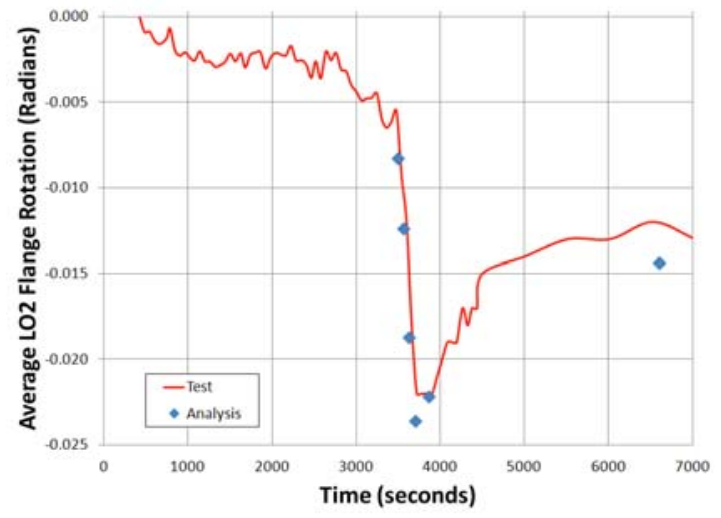

Figure 12. Tanking test average flange rotation

\section{B. Sub-Component Test Correlation}

Sub-component structural testing was performed at the Marshall Space Flight Center consisting of a single stringer section of an intertank ${ }^{2}$. The test applied a radial load to the forward chord flange along with a flange rotation corresponding to the worst case chill-down case of 3700 seconds. The intertank section was bent over two mandrel points to simulate the bending that the intertank experiences during the chill-down transient. Instrumentation consisted of displacement gauges, strain gauges, as well as full field photogrametry measurement of strain and displacement. The flight stress analysis finite element model was used as the basis for performing a stress analysis of the test. The model was modified to reflect the test configuration and then correlated with the test results as described in reference 3 . The model was not successfully correlated until after the flight of STS-133, but the resulting correlation was very good. 


\section{Assembly Stress Studies}

Early in the investigation into the stringer cracks it was suspected that assembly stress was a contributing factor. There were a few previous instances of stringers cracking during manufacturing and there existed the possibility for stresses to develop based on the dimensional tolerances and sequence of the assembly process. The stress analysis was used to investigate the severity of three assumed initial assembly conditions. The conditions were assumed because actual assembly conditions were not measured, and it was problematic to determine one or more bounding design cases. Therefore, the results were for engineering reference only and could not be used for predicting a factor of safety against failure.

One condition of interest was the allowance of up to a 0.030 inch gap to exist between the stringer feet and the underlying structure. Gaps larger than 0.030 inch were to be filled with a shim. The stress analysis examined two possible gap conditions and how they affected the loads and stress in the stringer. The first condition represented a 0.030 inch gap at the bend in the feet approximately eight inches from the stringer forward end. The gap linearly tapered down to a closed state six inches on either side of this point. The second condition represented a 0.030 inch gap at the very forward end of the stringer that tapered down to a closed state at the bend in the feet. Figure 13 and Figure 14 show the sidewall radial force and stringer foot path hoop stress for these two gap conditions. Each plot shows the results with just the gap closed at room temperature and the results at 3700 seconds, along with the baseline case at 3700 seconds.

The radial force and stress in the feet is higher at the location of the gap than other areas for the installed room temperature condition. The gap at the bend in the feet produces slightly higher loads and stress than the gap at the end of the stringer. The gap at the bend in the feet does not affect the loads and stress at 3700 seconds. The gap at the end adds to the stress and loads for the 3700 second case at the first three fasteners, but the peak values are only slightly increased.

These results indicate that an allowed gap of 0.030 inch not at the end of the stringer is benign. If the gap exists at the end of the stringer, the gap adds to the severity of the peak stress state but not substantially.
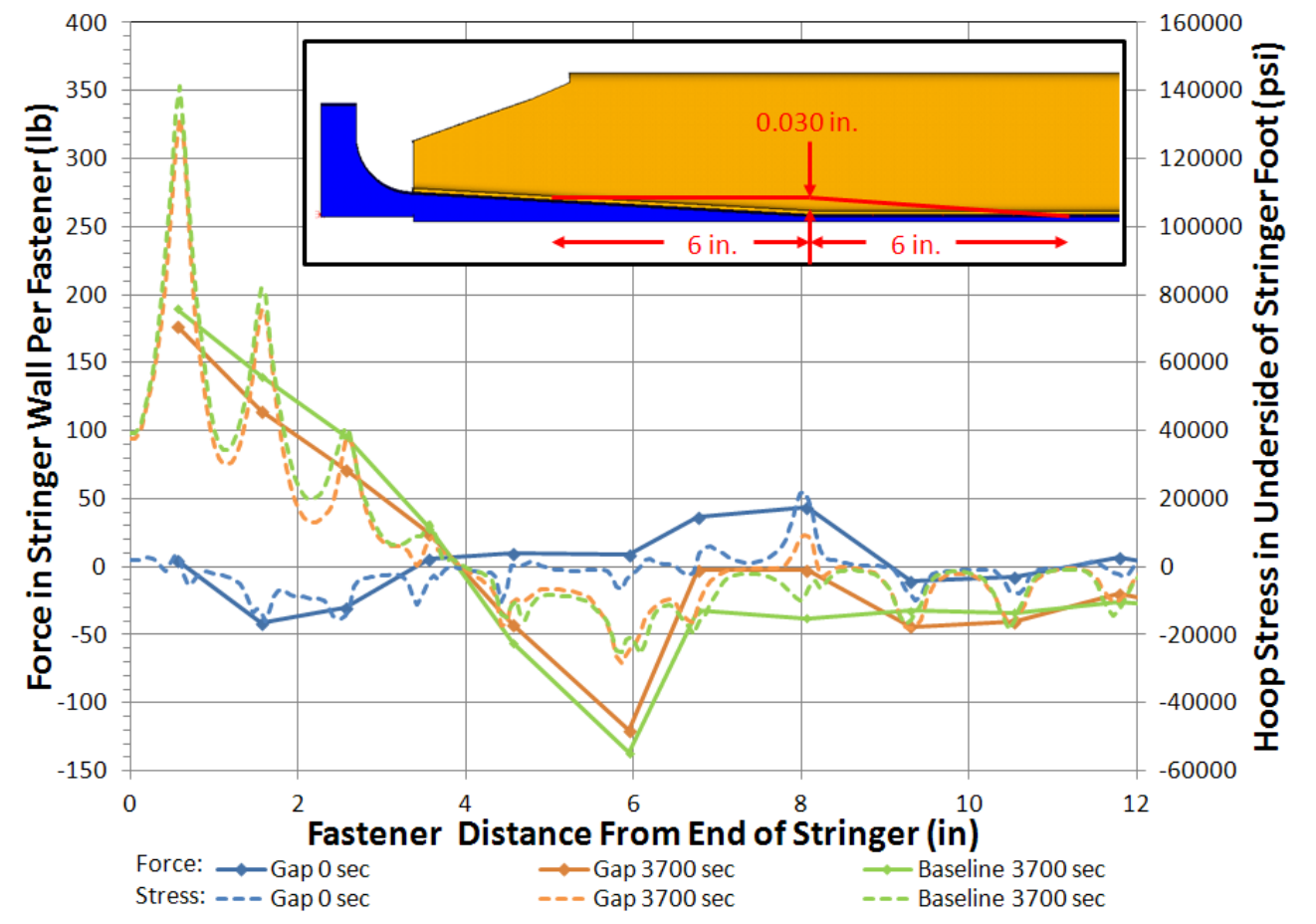

Figure 13. Gap at stringer foot bend results. 


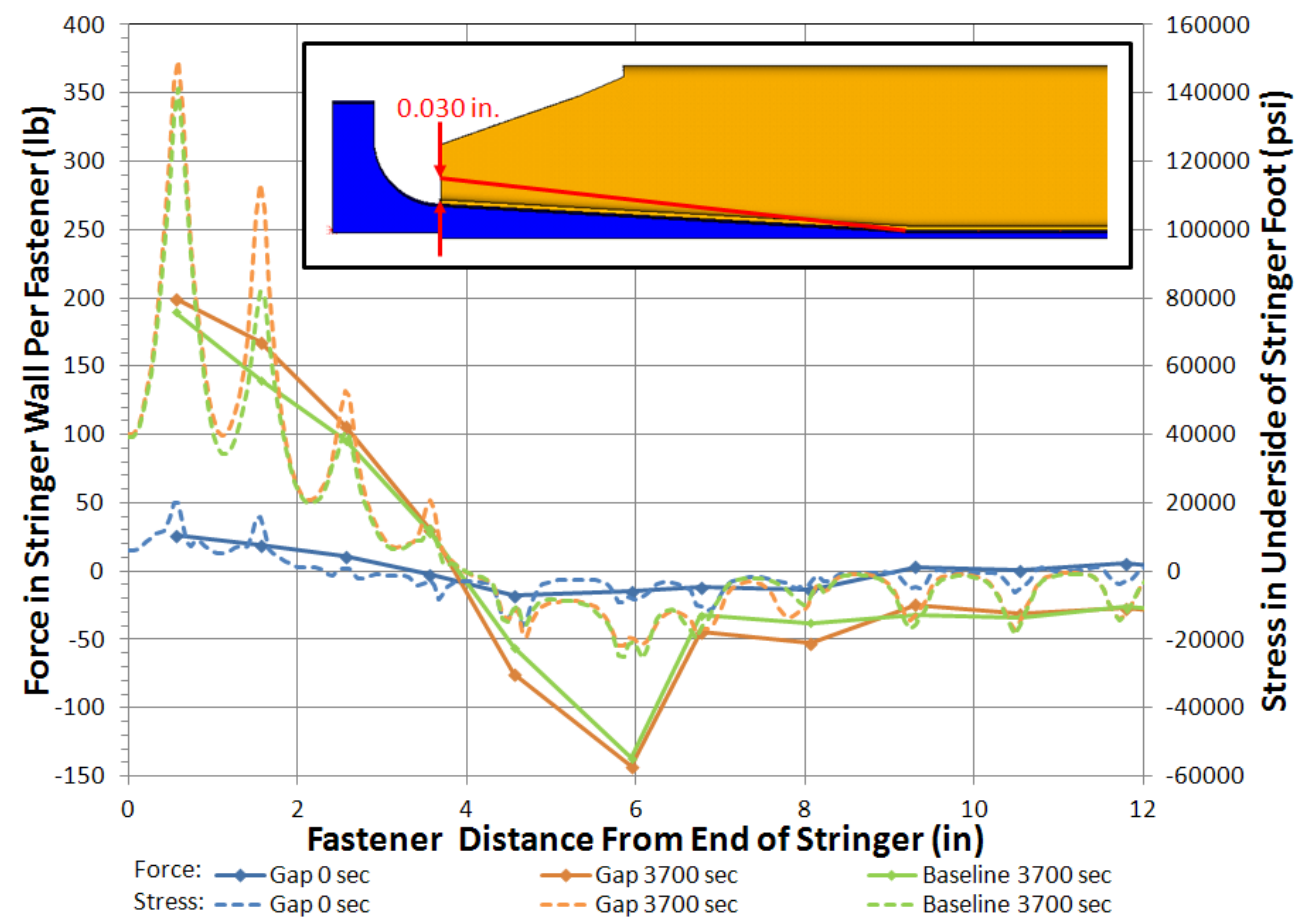

Figure 14. Gap at stringer end results.

Another assembly condition that was examined was what was referred to as a "toe forward" condition. This condition is characterized by the outboard edge of the forward ends of the stringer feet being out-of-plane and more radially inward than other regions of the bottom of the feet (Figure 15) This condition was considered one of the more severe conditions relative to the stringer crack issue, since installation of the stringer to the intertank would force the feet at the ends of the stringer to bend in a manner that would introduce local bending in the feet in the same location and direction as experienced during chill-down.

The "toe forward" assembly condition was evaluated by considering a scenario where all of the rivets and hilocks (fasteners used to attach the majority of the stringer to the skin) were installed, and then the five lockbolts (five forward most fasteners used to attach the stringer to the skin) were installed one at a time (modeled as two at a time since the model used one-half symmetry) from aft to forward. The toe of the stringer foot was set to be 0.050 inch forward of the heel of the feet based on measurement of an existing non-installed stringer. Figure 16 shows how the gap under the foot was closed as each fastener was installed. Figure 17 shows the

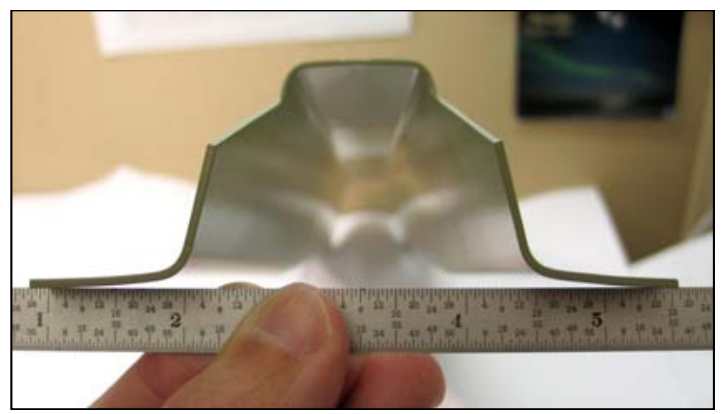

Figure 15. Stringer "toe forward" condition.

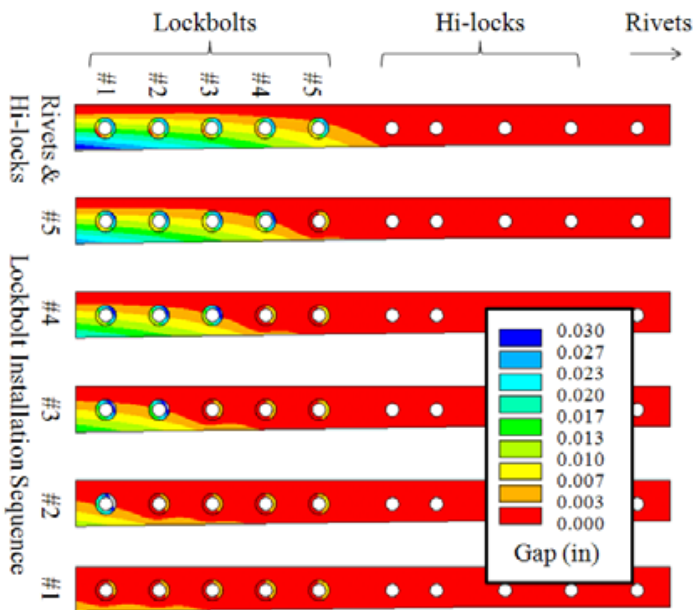

Figure 16. “Toe forward" gap under stringer foot during lockbolt installation sequence. 
stress along the path on the underside of the foot after installation of each lockbolt. The stress levels associated with this assembly condition are more than twice as high as the two gap conditions considered above, indicating that this type of condition would negatively affect the strength capability during chill-down.

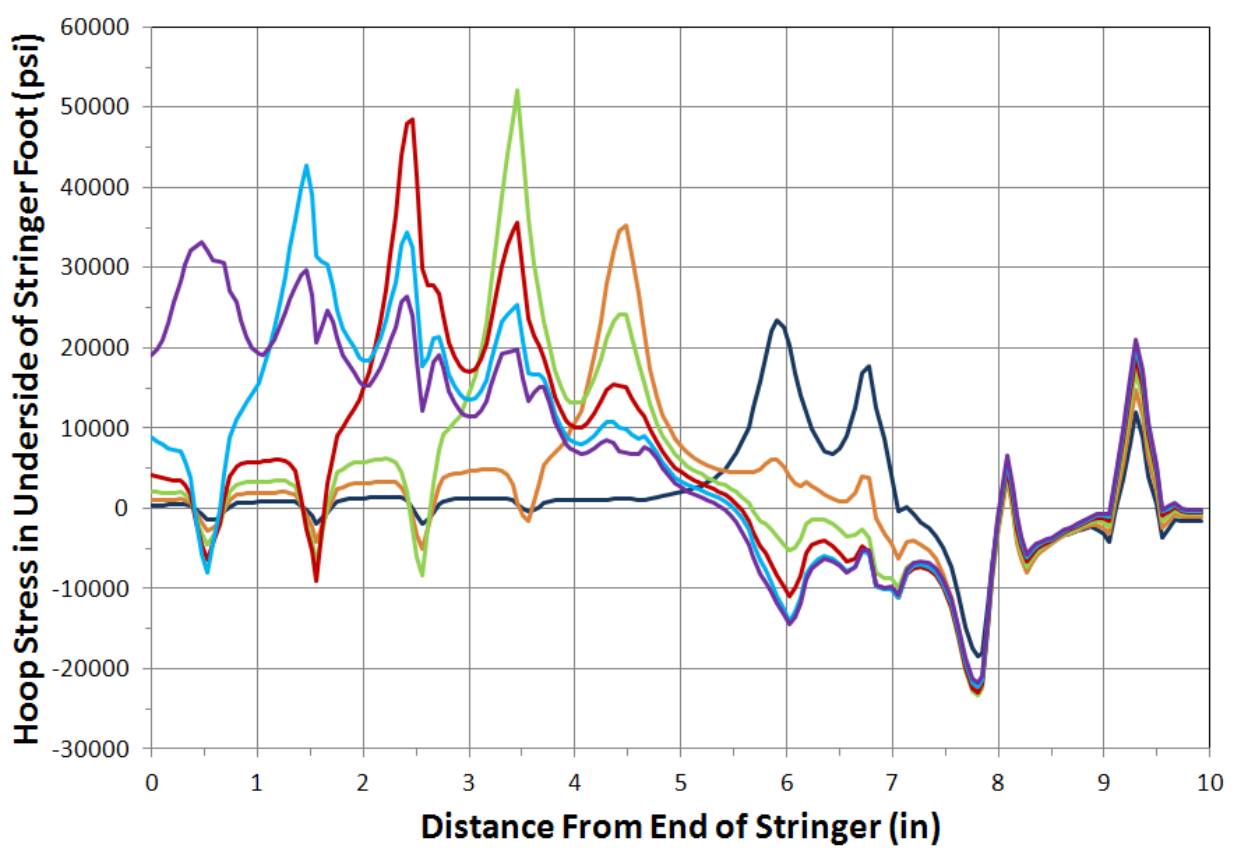

—Rivets \& Hi-locks -Lockbolt\#5 -Lockbolt\#4 -Lockbolt\#3 - Lockbolt\#2 -Lockbolt\#1

Figure 17. “Toe forward” gap results.

\section{Radius Block Reinforcement Assessment}

Following the tanking test, an x-ray inspection of the forward ends of all accessible stringers was performed which revealed that three additional stringers were also cracked. This finding, along with other information discovered during the investigation regarding the pedigree of the stringers, pointed to a potential issue with the material behavior of two stringer manufacturing lots that were used for the STS-133 External Tank. Thus it was concluded that stringer cracking was a potential issue for many of the other stringers installed on the tank. The External Tank program then decided to proactively reinforce the forward ends of the stringer feet. This involved installing a thick backer plate, referred to as a radius block, to both feet of every accessible stringer. The radius block extended from the second to seventh fastener from the stringer forward end (Figure 18). Because of internal access issues, the forward most fastener was not removed, so the radius block did not cover this most highly stressed region.

The radius block was added to the stress analysis model to assess its effectiveness (Figure 19). Contact was modeled between the radius block and stringer. As expected, the results show that the stress level in the stringer feet directly under the radius block was significantly reduced. At the forward most fastener the stress level was also reduced. Figure 20 shows the stringer sidewall force and foot stress with and without the radius block at 3700 seconds. The sidewall force at the forward most fastener is reduced, but the next fastener location picks up additional load. The elastic stress level at the forward most fastener is reduced by approximately half. These results indicated that although the radius block was not able to be installed over the first fastener, it still significantly reduced the stress level at this highly stressed region.

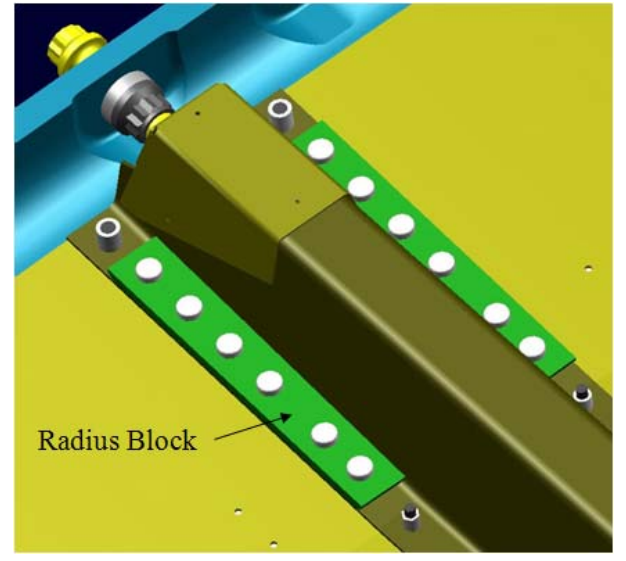

Figure 18. Radius block modification. 
Some additional peak stress and strain criteria at the forward most fastener were compared with and without a radius block. These included the peak first principal stress from the elastic model and the peak equivalent strain from the model using a non-linear stress-strain material property curve. The peak values are the peak values around the fastener hole ignoring the results in the first row of elements around the hole. Table 1 shows the relative factor for each criterion. The minimum factor is 1.51 , which indicates that the repaired stringer should be approximately that much stronger than an unrepaired stringer.

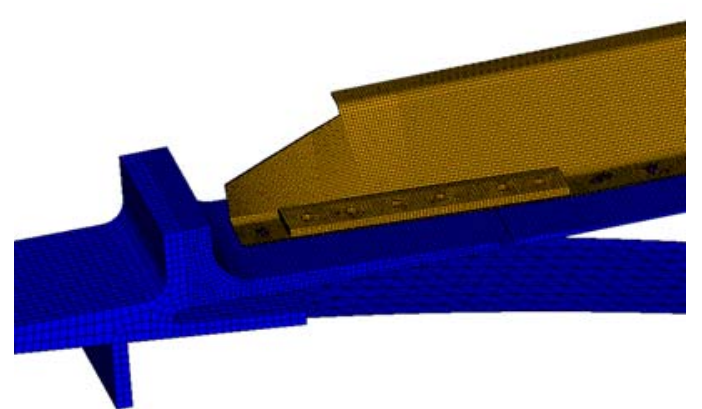

Figure 19. Finite element model with radius block.

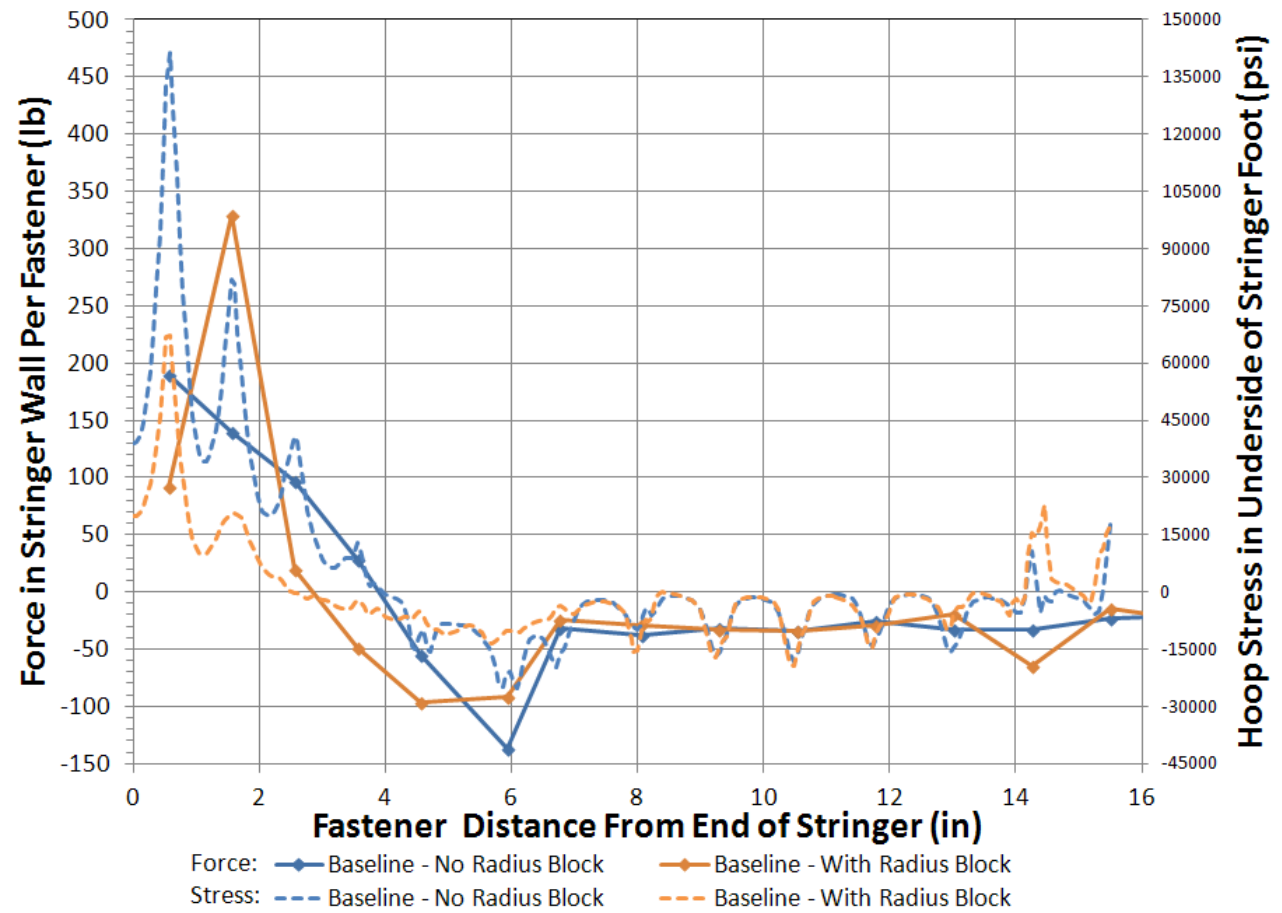

Figure 20. Comparison of results with and without radius block repair. 
Table 1. Comparison of stress and strain criteria with and without radius block repair.

\begin{tabular}{|c|c|c|c|c|c|}
\hline $\begin{array}{c}\begin{array}{c}\text { Number } \\
\text { of Skin } \\
\text { Doublers }\end{array} \\
\end{array}$ & Criteria & $\begin{array}{c}\text { Material } \\
\text { Model }\end{array}$ & $\begin{array}{l}\text { Radius } \\
\text { Blocks }\end{array}$ & Value & $\begin{array}{c}\text { Ratio of Value } \\
\text { With to Without } \\
\text { Radius Block } \\
\end{array}$ \\
\hline \multirow{2}{*}{0} & \multirow{2}{*}{$\begin{array}{l}\text { Peak 1st Principal Stress } \\
\text { (psi) }\end{array}$} & \multirow{2}{*}{ Elastic } & Without & 208,045 & \multirow{2}{*}{1.70} \\
\hline & & & With & 122,499 & \\
\hline \multirow{2}{*}{0} & \multirow{2}{*}{$\begin{array}{l}\text { Peak Total Equivalent } \\
\text { Strain (in/in) }\end{array}$} & \multirow{2}{*}{ Plastic } & Without & 0.0346 & \multirow{2}{*}{1.51} \\
\hline & & & With & 0.0229 & \\
\hline \multirow{2}{*}{1} & \multirow{2}{*}{$\begin{array}{l}\text { Peak 1st Principal Stress } \\
\text { (psi) }\end{array}$} & \multirow{2}{*}{ Elastic } & Without & 238,604 & \multirow{2}{*}{1.74} \\
\hline & & & With & 137,091 & \\
\hline \multirow{2}{*}{1} & \multirow{2}{*}{$\begin{array}{c}\text { Peak Total Equivalent } \\
\text { Strain (in/in) }\end{array}$} & \multirow{2}{*}{ Plastic } & Without & 0.0463 & \multirow{2}{*}{1.72} \\
\hline & & & With & 0.0269 & \\
\hline \multirow{2}{*}{2} & \multirow{2}{*}{$\begin{array}{l}\text { Peak 1st Principal Stress } \\
\text { (psi) }\end{array}$} & \multirow{2}{*}{ Elastic } & Without & 259,954 & \multirow{4}{*}{2.08} \\
\hline & & & With & 124,805 & \\
\hline \multirow{2}{*}{2} & \multirow{2}{*}{$\begin{array}{l}\text { Peak Total Equivalent } \\
\text { Strain (in/in) }\end{array}$} & \multirow{2}{*}{ Plastic } & Without & 0.0500 & \\
\hline & & & With & 0.0232 & \\
\hline
\end{tabular}

The sub-component structural test configurations included stringers with and without radius blocks, which were loaded until failure occurred in the stringer. Table 2 compares the failure load for all of these tests that exhibited the same failure mode of breaking in the stringer feet ${ }^{3}$. The last column lists the average relative strength of the test specimens with radius blocks compared to the test specimens of the same skin doubler configuration. The ratios are comparable to the analysis minimum predicted factors for the zero and one doubler configurations. The single test result for the two doubler configuration with radius blocks shows less strength increase than predicted and does not agree with the trend of increasing strength with increasing numbers of doubler skins.

Table 2. Stringer sub-component structural test results with and without radius block repair.

\begin{tabular}{|c|c|c|c|c|}
\hline \multicolumn{2}{|c|}{ Configuration } & \multirow[b]{2}{*}{$\begin{array}{l}\text { Load at } \\
\text { Failure } \\
\text { (lb) }\end{array}$} & \multirow[b]{2}{*}{$\begin{array}{l}\text { Configuration } \\
\text { Average Load at } \\
\text { Failure (lb) }\end{array}$} & \multirow[b]{2}{*}{$\begin{array}{l}\text { Ratio of Average Load at } \\
\text { Failure With Radius Block } \\
\text { to Without Radius Block }\end{array}$} \\
\hline $\begin{array}{l}\text { Number of } \\
\text { Skin } \\
\text { Doublers }\end{array}$ & $\begin{array}{c}\text { Radius } \\
\text { Block }\end{array}$ & & & \\
\hline 0 & No & 1966 & \multirow{4}{*}{1728} & \multirow{6}{*}{1.67} \\
\hline 0 & No & 1655 & & \\
\hline 0 & No & 1641 & & \\
\hline 0 & No & 1652 & & \\
\hline 0 & Yes & 2965 & \multirow{2}{*}{2886} & \\
\hline 0 & Yes & 2807 & & \\
\hline 1 & No & 1539 & \multirow{2}{*}{1951} & \multirow{4}{*}{1.74} \\
\hline 1 & No & 2363 & & \\
\hline 1 & Yes & 3424 & \multirow{2}{*}{3394} & \\
\hline 1 & Yes & 3365 & & \\
\hline 2 & No & 2293 & 2293 & \multirow{2}{*}{1.34} \\
\hline 2 & Yes & 3067 & 3067 & \\
\hline
\end{tabular}

\section{Conclusion}

The STS-133 stringer crack investigation concluded that there were two primary factors which likely contributed to the observed stringer cracks: 1) two manufacturing lots were produced with low material toughness ${ }^{4}$, and 2) considerable assembly stress levels were likely present. While the stress analysis was able to assess the relative severity of some assembly conditions, it was not possible to credibly estimate the assembly stress level for the 
stringers on the intertank due to a lack of knowledge of the actual assembly conditions. However, the analysis was very beneficial in understanding the loading experienced by the stringer during tanking and flight and how the stringer behaved under those loads. In addition, when radius blocks were added, the analysis provided a quantitative estimate of the relative strength improvement of the reinforcement, which helped to develop the flight rationale needed to show the tank had adequate capability.

\section{References}

${ }^{1}$ Oliver, S. T., "STS-133/ET-137 Tanking Test Photogrammetry Assessment,” 53 ${ }^{\text {rd }}$ AIAA Structures, Structural Dynamics, and Materials Conference, AIAA, Reston, VA, 2012.

${ }^{2}$ Saxon, J.B., Swanson, G. R., Ondocsin, W. P., Boles, T. B., and Wingate, R. J., "Stringer Bending Test Helps Diagnose and Prevent Cracks in the Space Shuttle's External Tank," 53 ${ }^{\text {rd }}$ AIAA Structures, Structural Dynamics, and Materials Conference, AIAA, Reston, VA, 2012.

${ }^{3}$ Phillips, D. R, Saxon, J. B., and Wingate, R. J., "Test-Analysis Correlation of the Single Stringer Bending Tests for the Space Shuttle ET-137 Intertank Stringer Crack Investigation,” $53^{\text {rd }}$ AIAA Structures, Structural Dynamics, and Materials Conference, AIAA, Reston, VA, 2012.

${ }^{4}$ Piascik, R. S., “Space Transportation System (STS)-133/External Tank (ET)-137 Intertank (IT) Stringer Cracking Issue and Repair Assessment: Proximate Cause Determination and Material Characterization Study,” NASA TM-2011-217318, 2011. 


\title{
STS-133 Space Shuttle External Tank Intertank Stringer Crack Investigation Stress Analysis
}

\author{
Brian E. Steeve \\ NASA Marshall Space Flight Center \\ Huntsville, Alabama
}

$53^{\text {rd }}$ AIAA/ASME/ASCE/AHS/ASC Structures, Structural

Dynamics, and Materials Conference

Honolulu, Hawaii

April 23-26, 2012 


\section{Introduction}

- Cracks that developed in the STS-133 Space Shuttle External Tank intertank stringers during tanking prompted a repair and an investigation into the cause.

- Marshall Space Flight Center Engineering performed a stress analysis of the cracked hardware to understand its behavior under loading and to assess the effectiveness of the repair.

- This presentation provides an overview of the stress analysis.

Topics:

- Hardware

- Analysis Model

- Loading

- Baseline Results

-Assembly Studies

- Repair Assessment

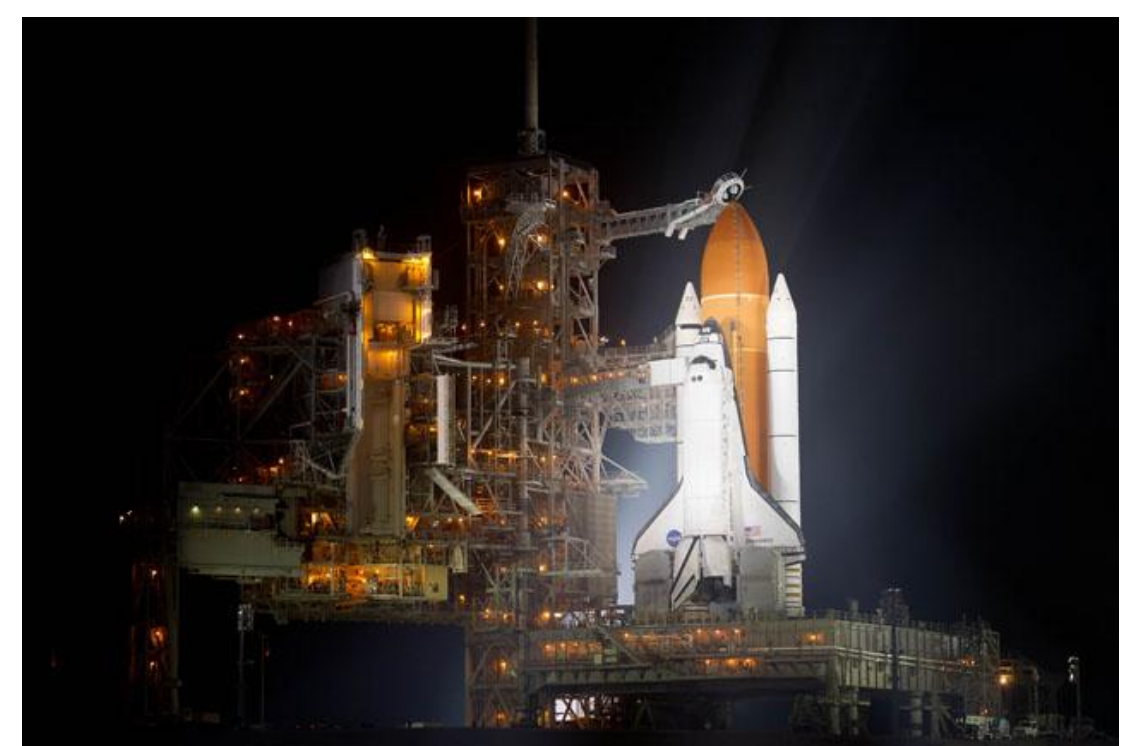

STS-133 On Pad 


\section{Hardware}

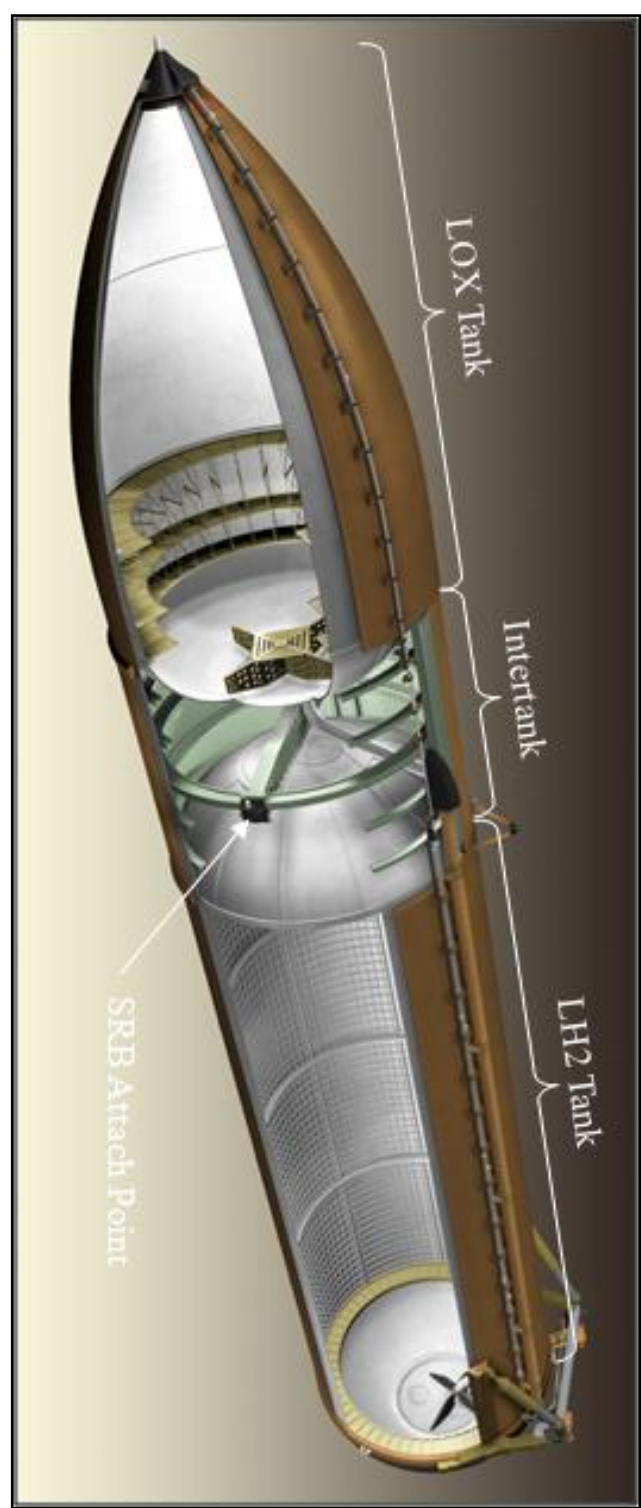

External Tank

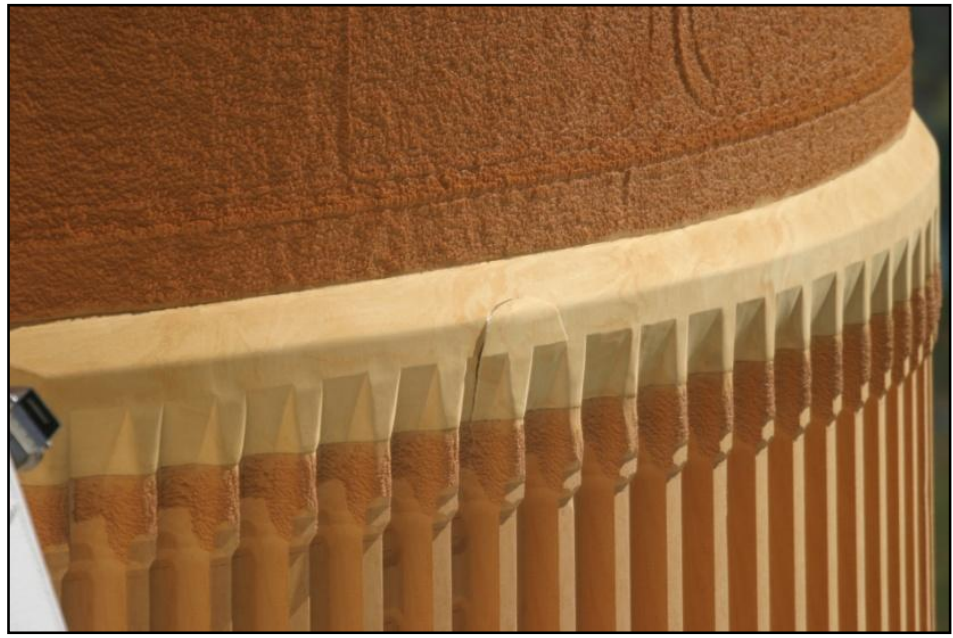

Intertank to LOX Tank Joint Region

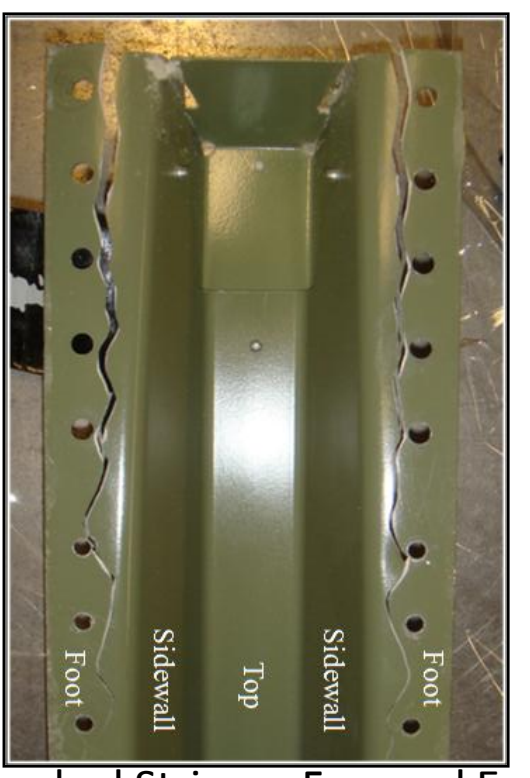

Cracked Stringer Forward End

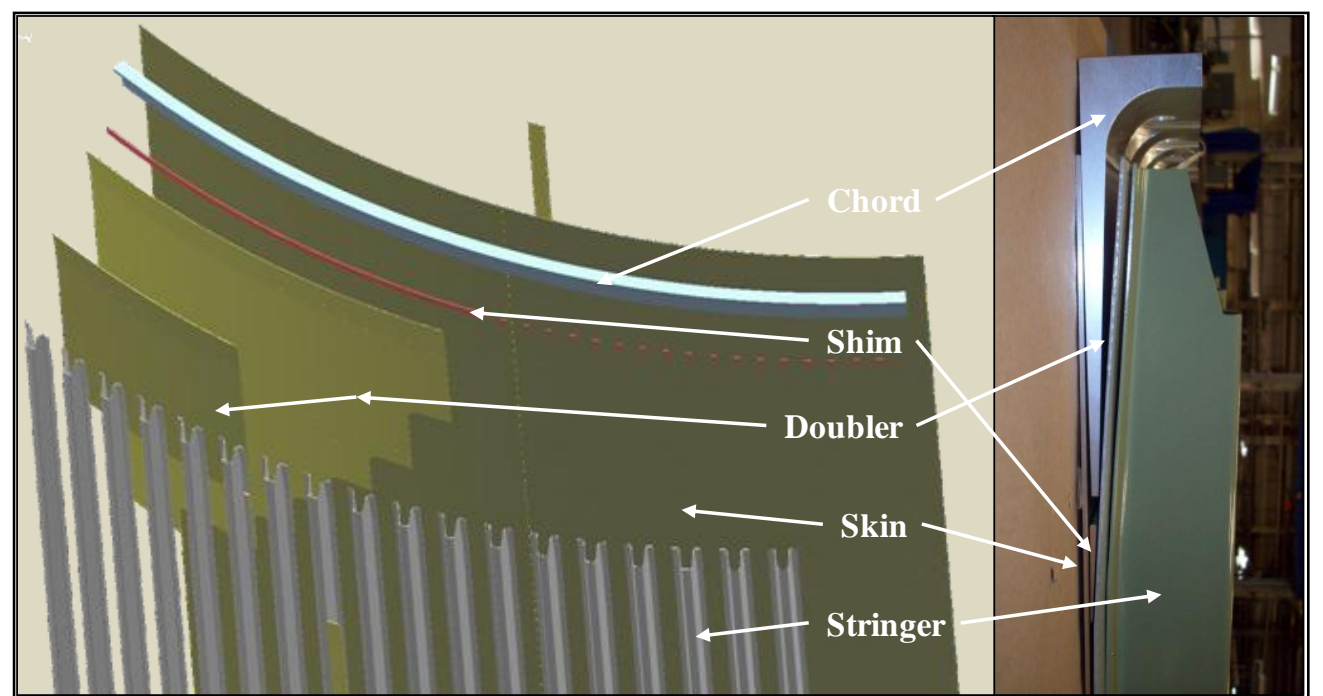

Intertank Skin/Stringer Panel Configuration 


\section{Analysis Model}

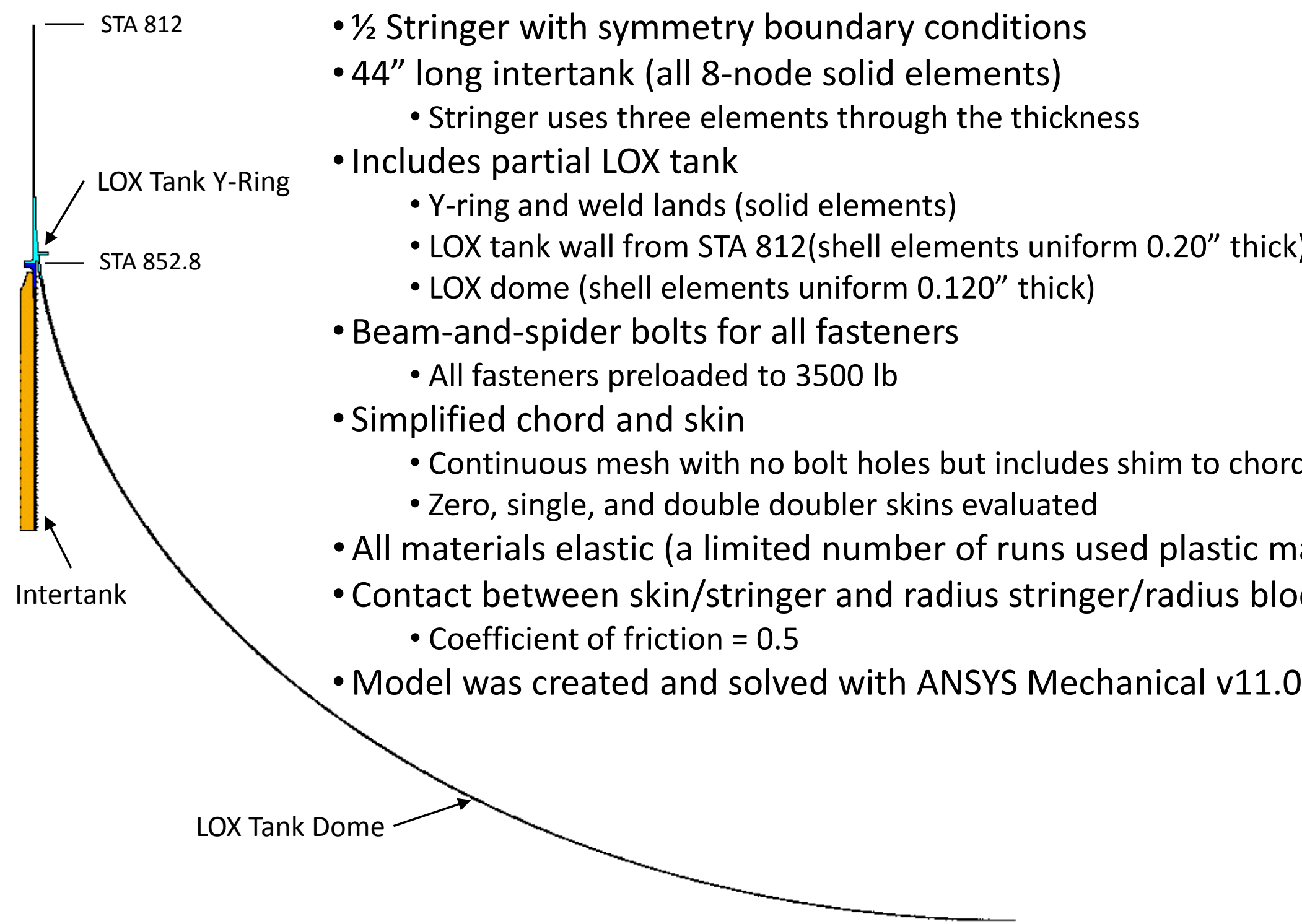

\section{Finite Element Model Description}

- $1 / 2$ Stringer with symmetry boundary conditions

-44" long intertank (all 8-node solid elements)

- Stringer uses three elements through the thickness

- Y-ring and weld lands (solid elements)

- LOX tank wall from STA 812(shell elements uniform 0.20" thick)

- LOX dome (shell elements uniform 0.120" thick)

- All fasteners preloaded to $3500 \mathrm{lb}$

- Simplified chord and skin

- Continuous mesh with no bolt holes but includes shim to chord gap

- Zero, single, and double doubler skins evaluated

- All materials elastic (a limited number of runs used plastic materials)

- Contact between skin/stringer and radius stringer/radius block

- Coefficient of friction $=0.5$ 


\section{Analysis Model}
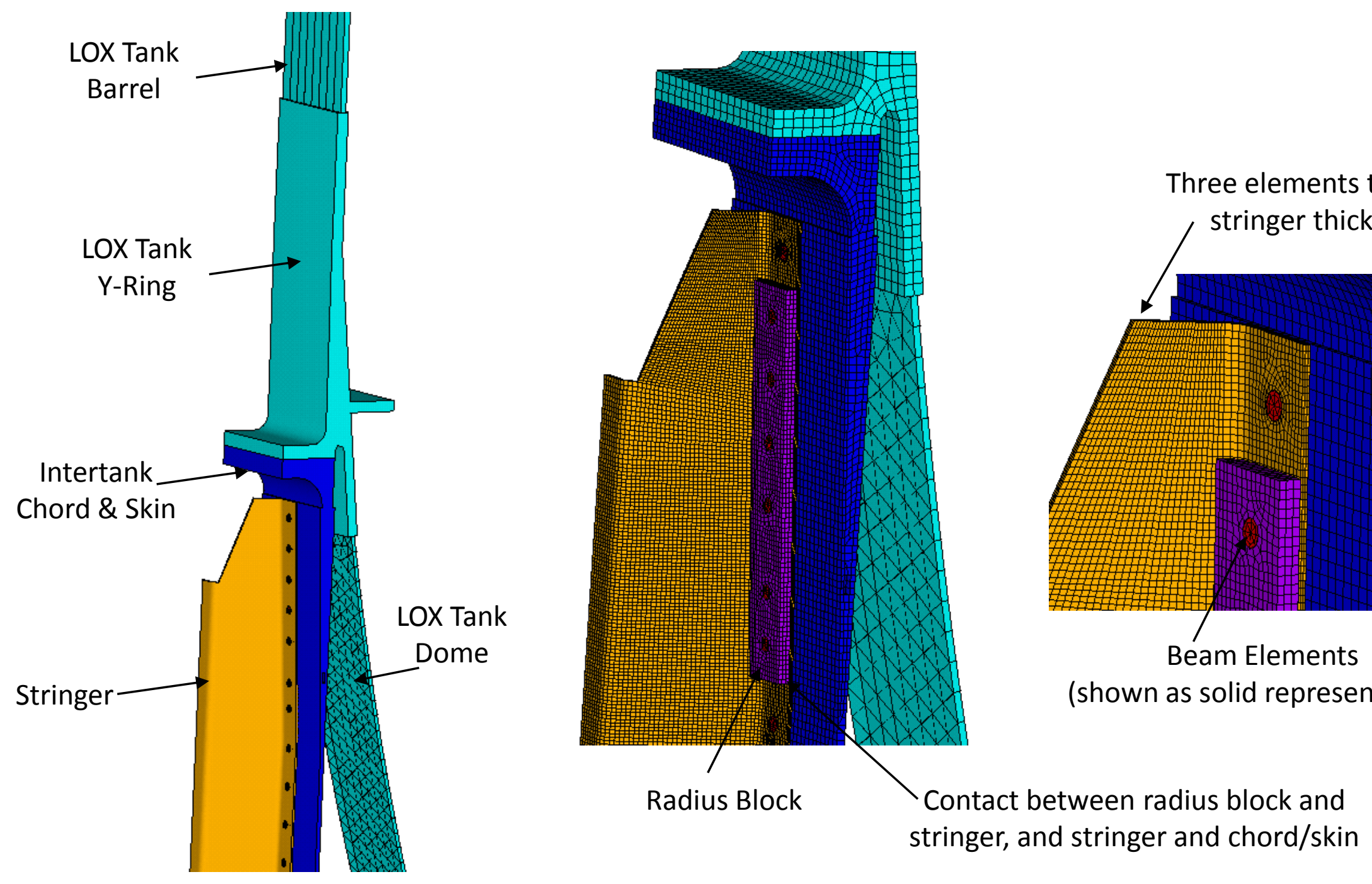


\section{Analysis Model}

Cylindrical Symmetry Conditions on Edges

Marshall Space Flight Center

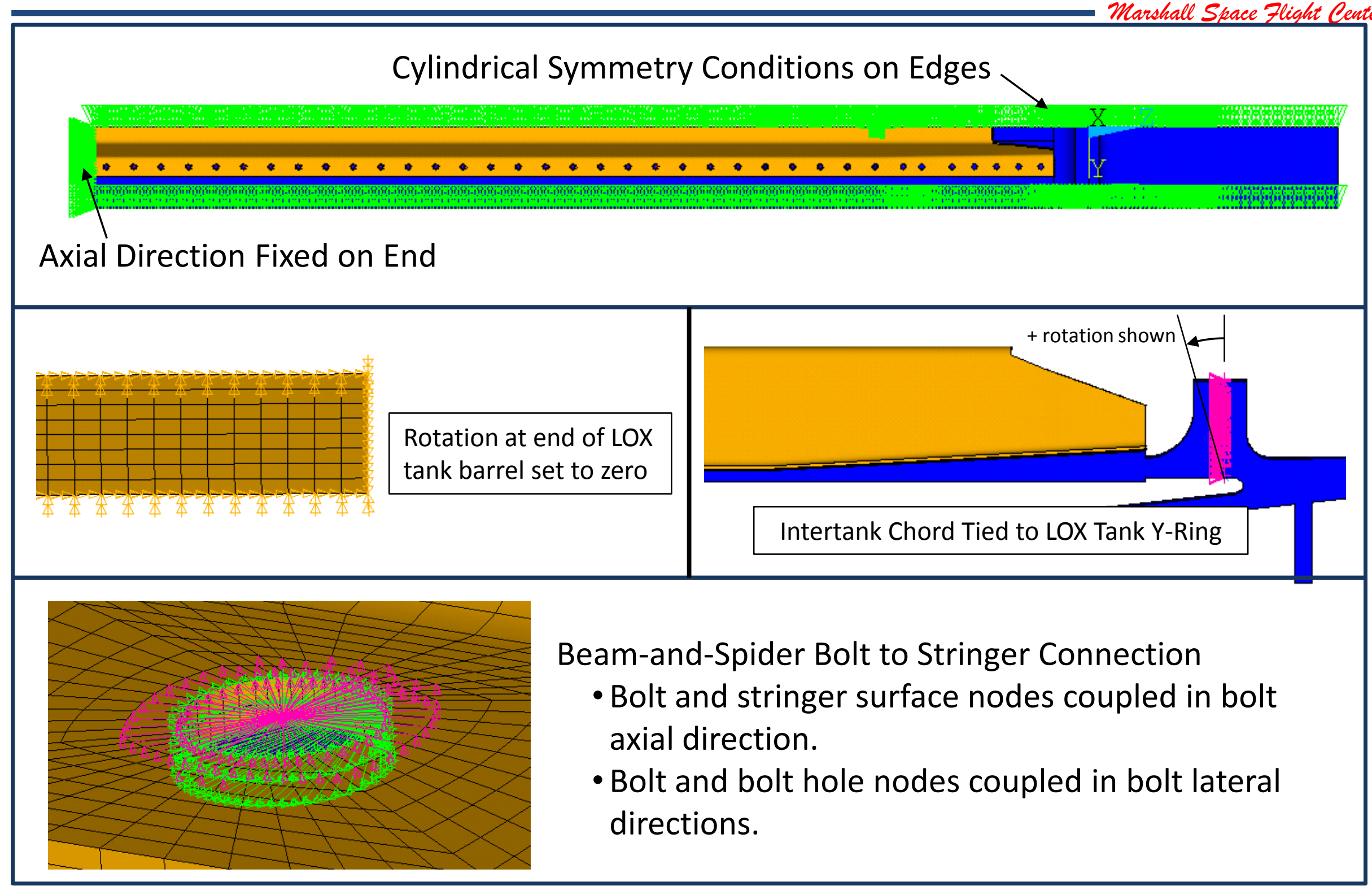




\section{Loading}

\section{Tanking Transient Thermal Profiles ( $\left.{ }^{\circ} \mathrm{F}\right)$}

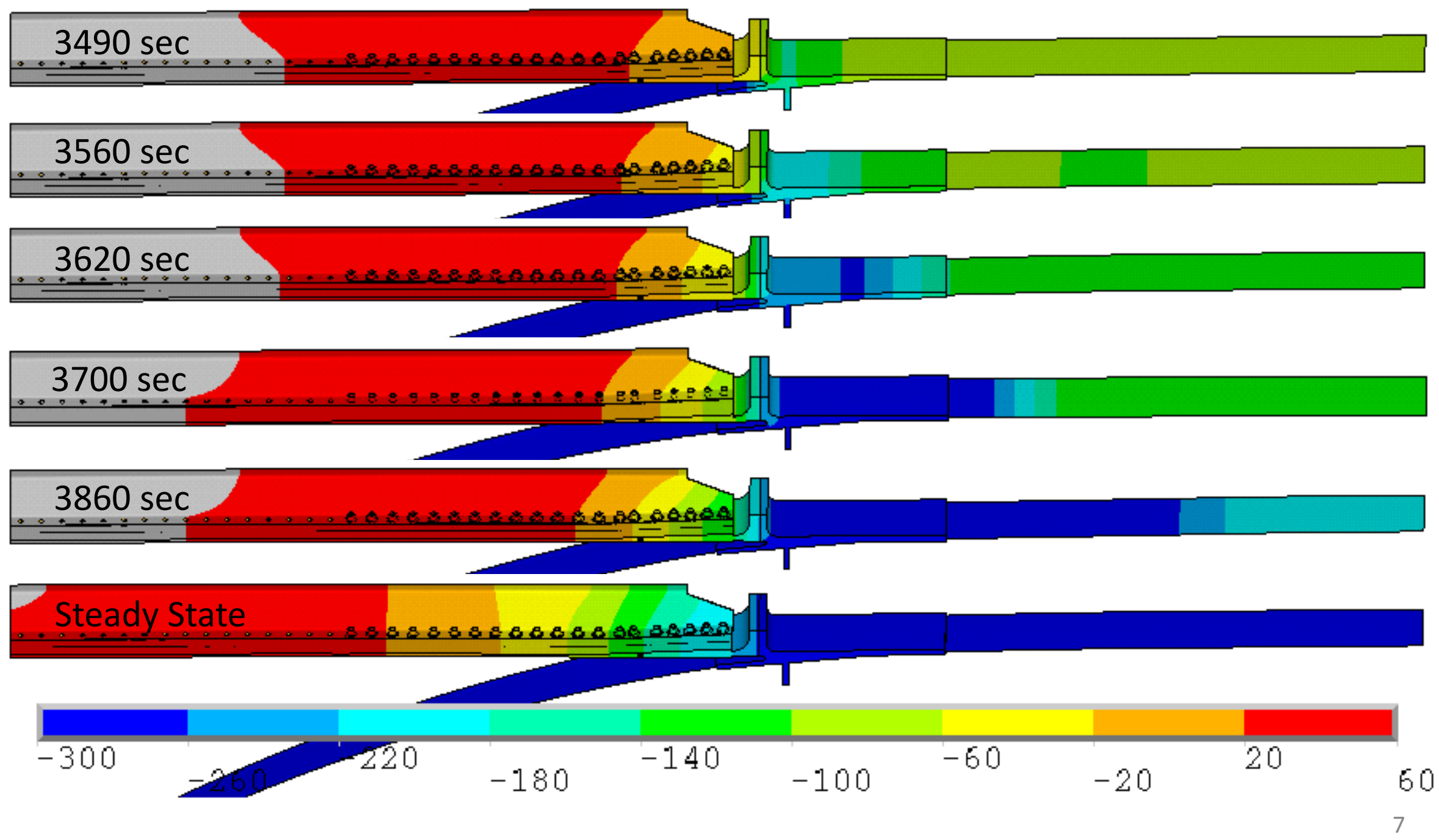




\section{Loading}

\section{Structural Line Loads}

- LOX tank pressure is applied to tank wall elements.

- Ullage pressure is based on the launch sequence (fill, pre-press, ascent).

- Head pressure is based on LO2 liquid level at a given time under 1g.

- The head pressure is reduced based on the axial stiffness of a particular azimuth location.

- Additional line load is applied to the intertank flange to equal the design limit compressive line load for both on-pad and ascent at a particular azimuth location.

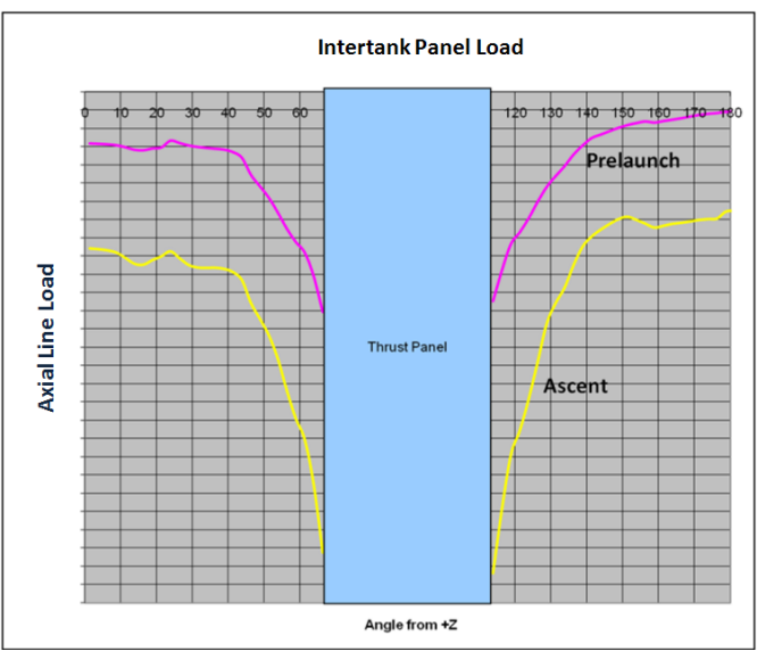




\section{Baseline Results}

- Thermal shrinkage of the LOX tank Y-Ring and intertank chord forces the forward end of the stringer to bend radially inward.

- The inward radial load is introduced through the fasteners into the foot of the stringer.

- Large bending stresses develop in the stringer foot around the inside of the fastener head.

- Peak elastic stress are above the material yield strength. In reality local yielding occurs around the fasteners.

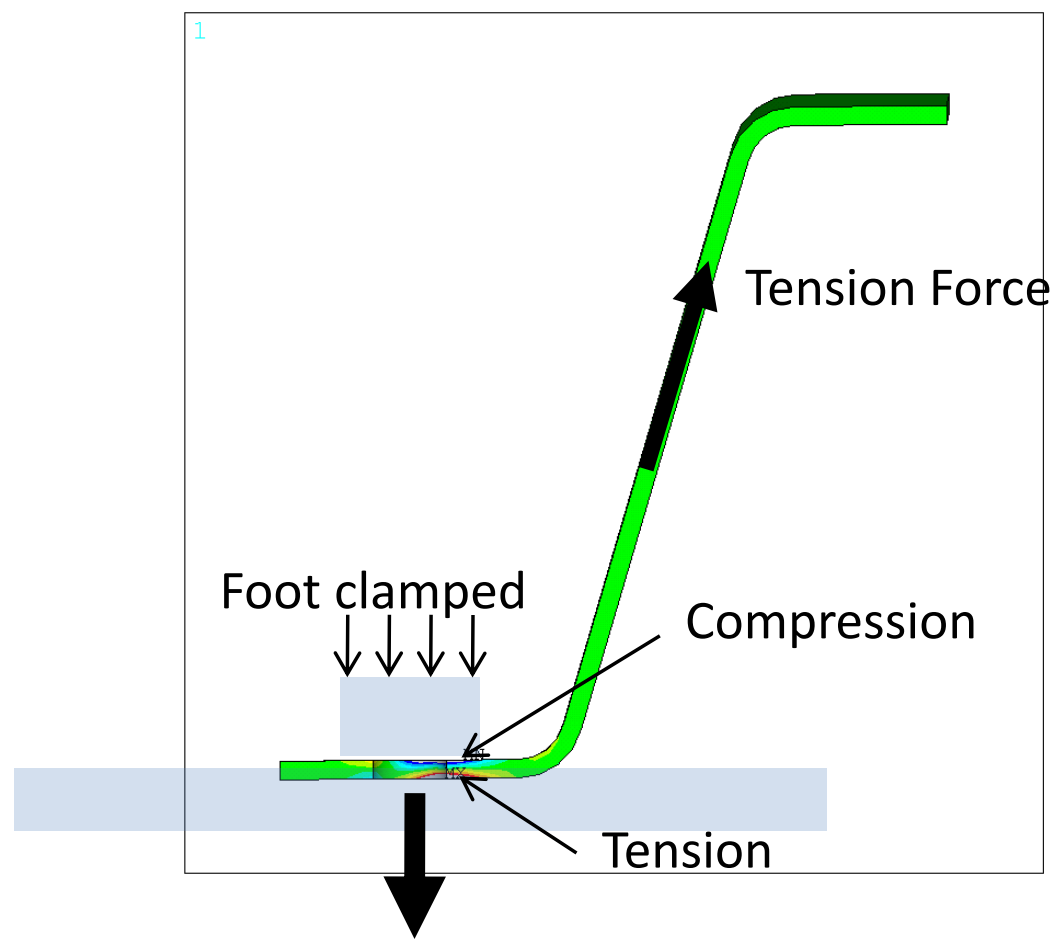




\section{Baseline Results}

- The behavior of the stringer along the axial direction was monitored by examining the force in the sidewall and the stress on the underside of the foot at various times.

- As the LOX tank y-ring shrinks an inward radial tensile load is applied to the first four fasteners which is reacted by a compressive load over the next few fasteners.

- During ascent the tip experiences a compressive load.

- High stress levels localized at each fastener location.
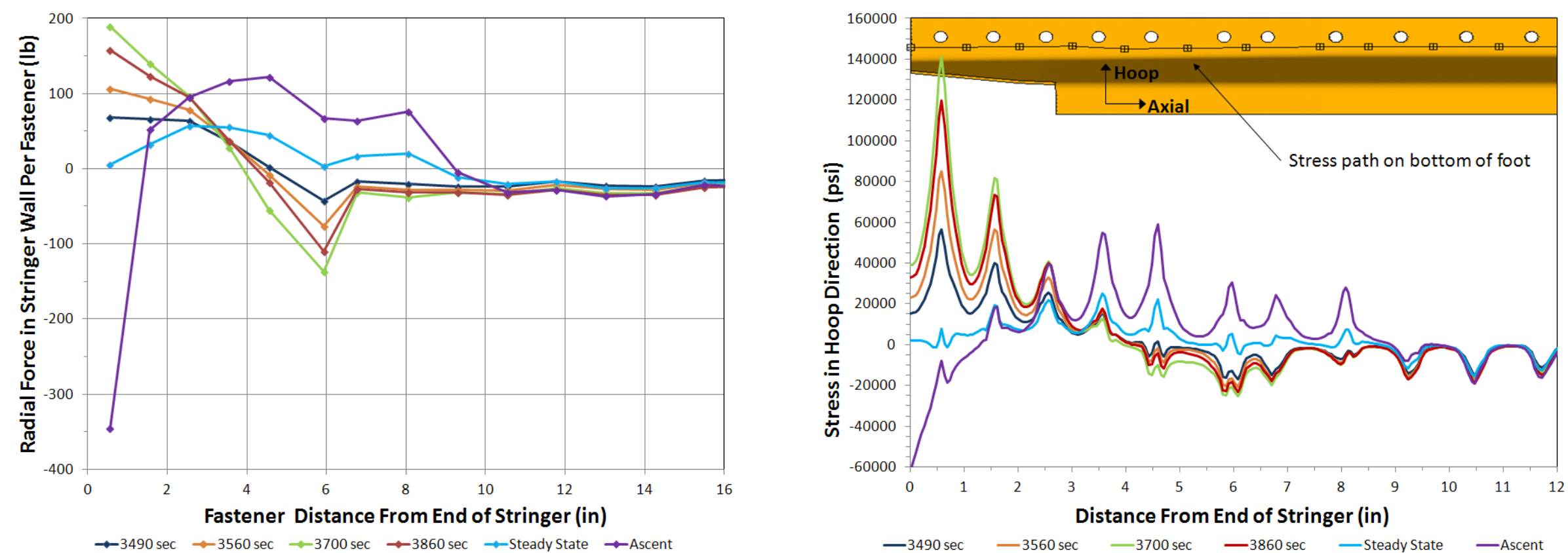

- Worst case loading occurs at 3700 seconds (after start of tank fill process)

- STS-133 crack occurred at 3599 seconds 


\section{Model Correlation}

\section{Tanking Test}

- Optical measurement of forward intertank region displacements during tanking test provided flange radial displacement and rotation data.

-Analysis results compared well with test data.

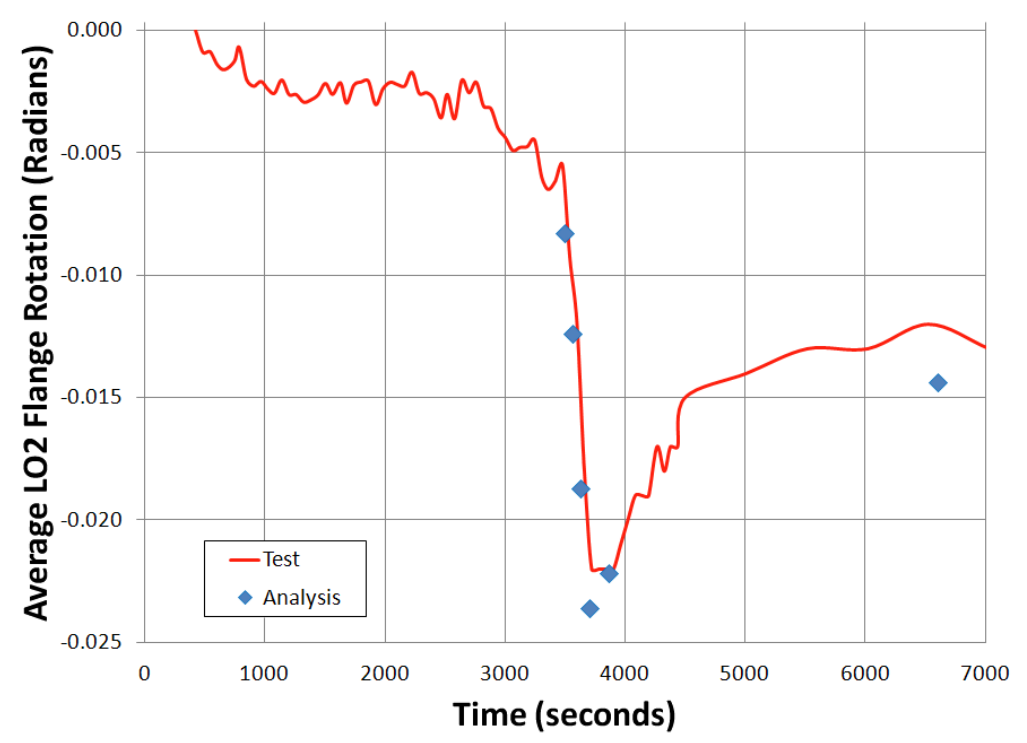

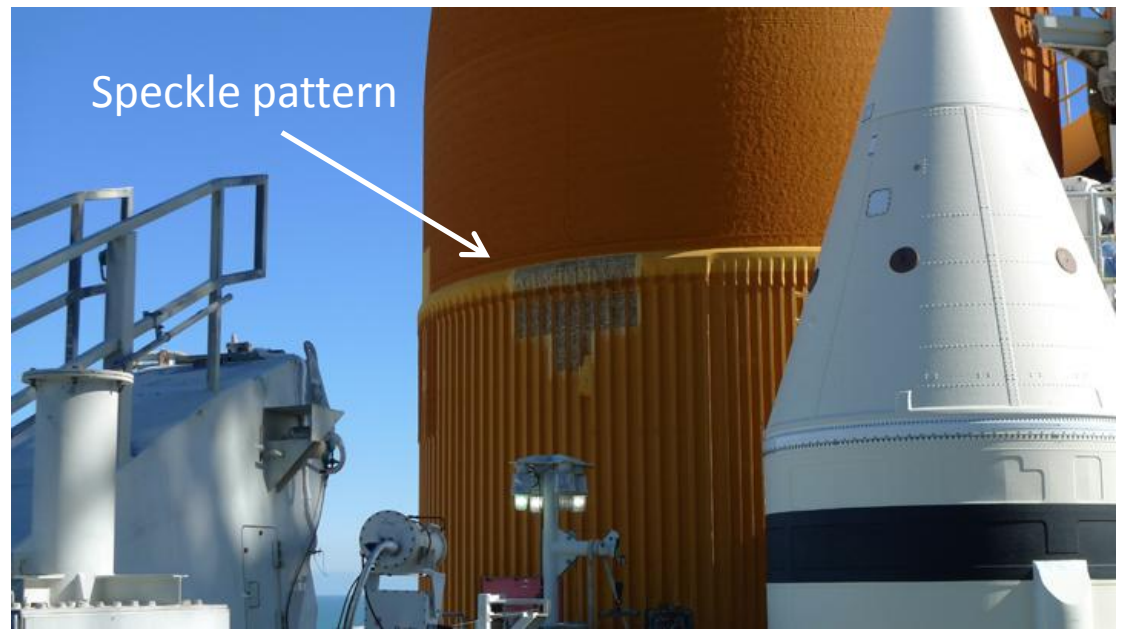

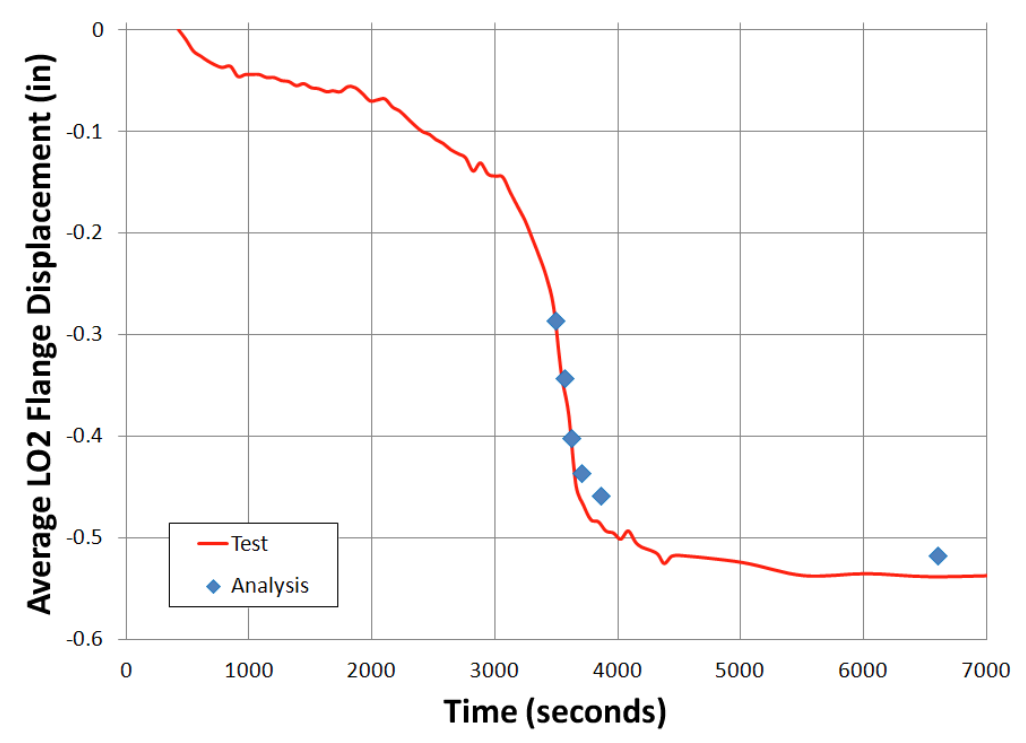




\section{Assembly Studies}

- Three assembly conditions were considered where an assumed initial gap under the foot was closed by fastener preload.

- Gap at bend and end associated with the manufacturing allowable gap.

- Actual as-installed conditions were not recorded.

- Unable to assess as-built stringers and it is problematic to come up with a bounding initial condition.

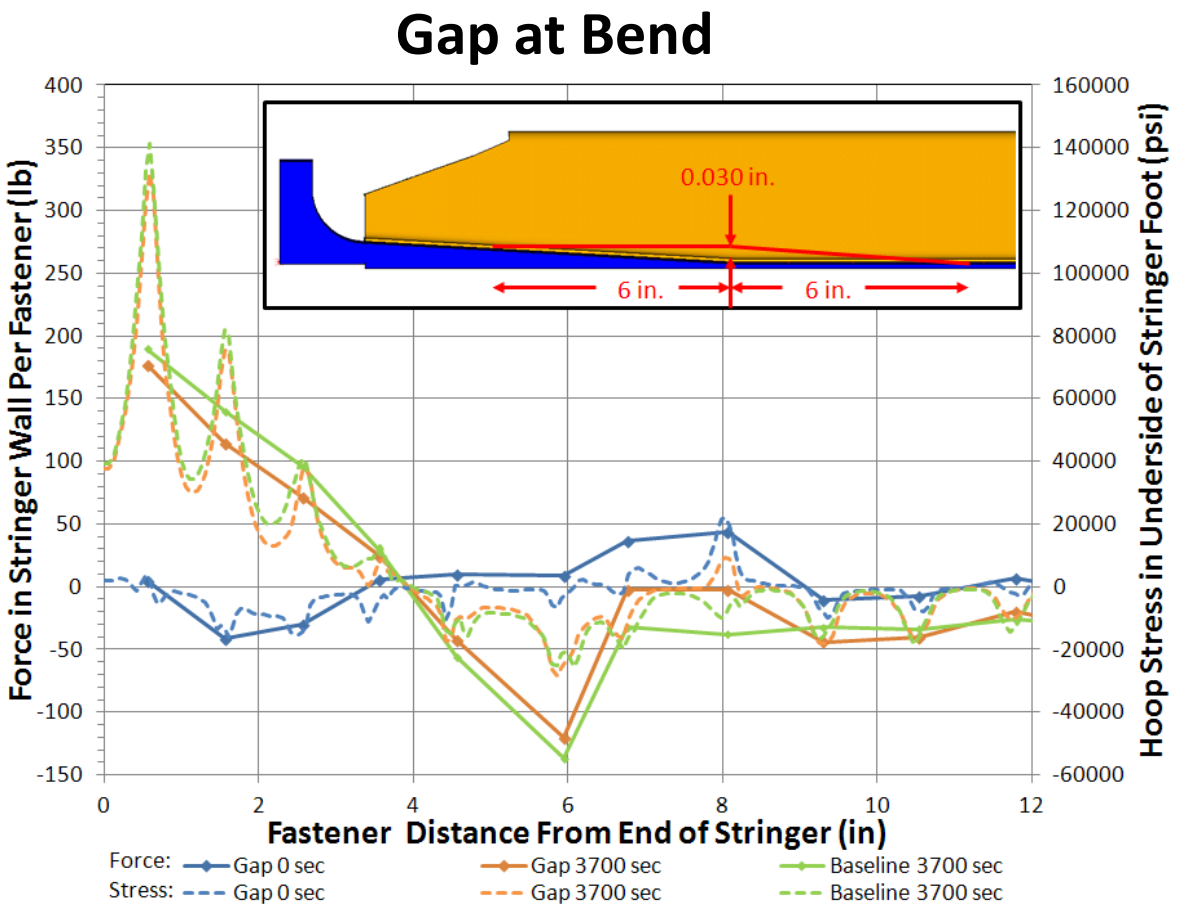

Assembly stress is benign

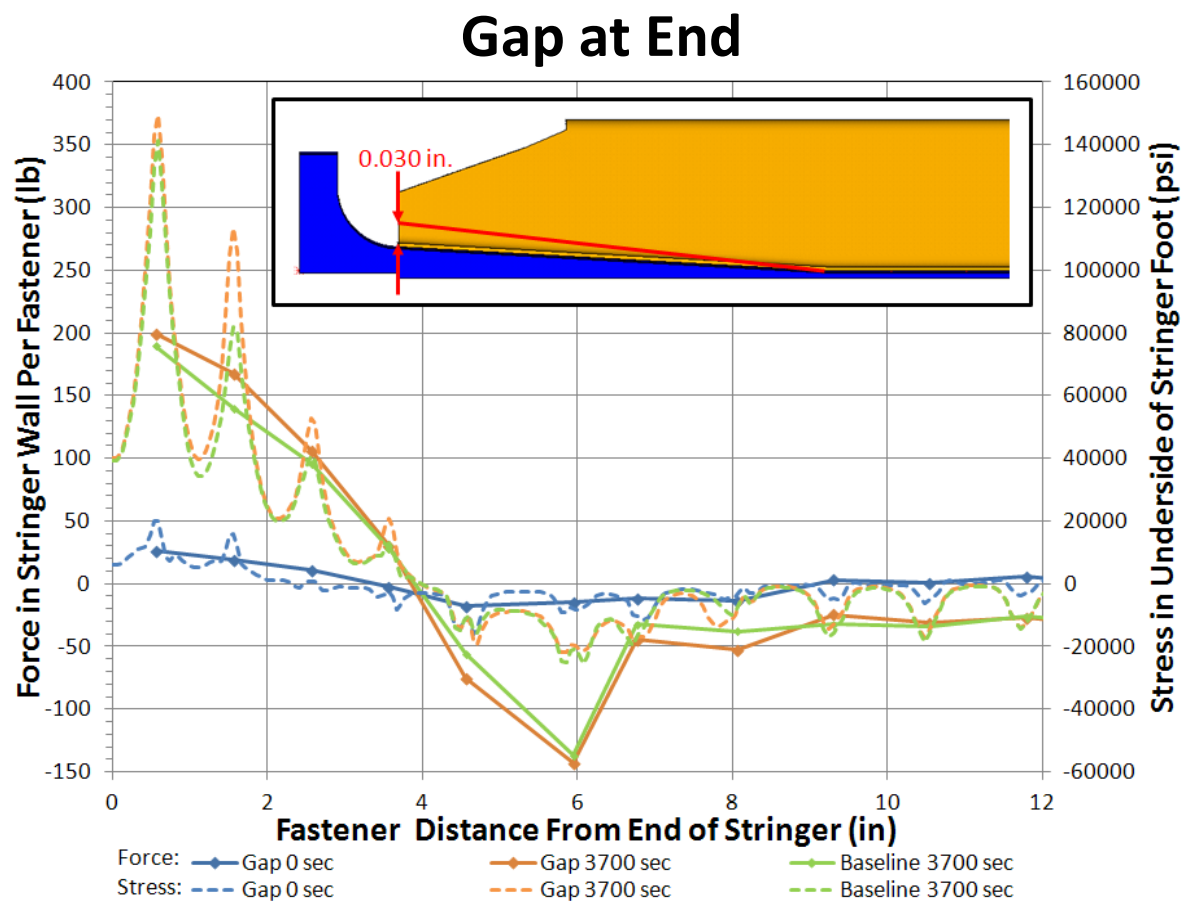

Assembly stress is small 


\section{Assembly Studies}

\section{"Toe Forward"}

- Based on observed condition.

- Toe of foot is radially inward relative to the heel.

- Preload applied one Lockbolt at a time.

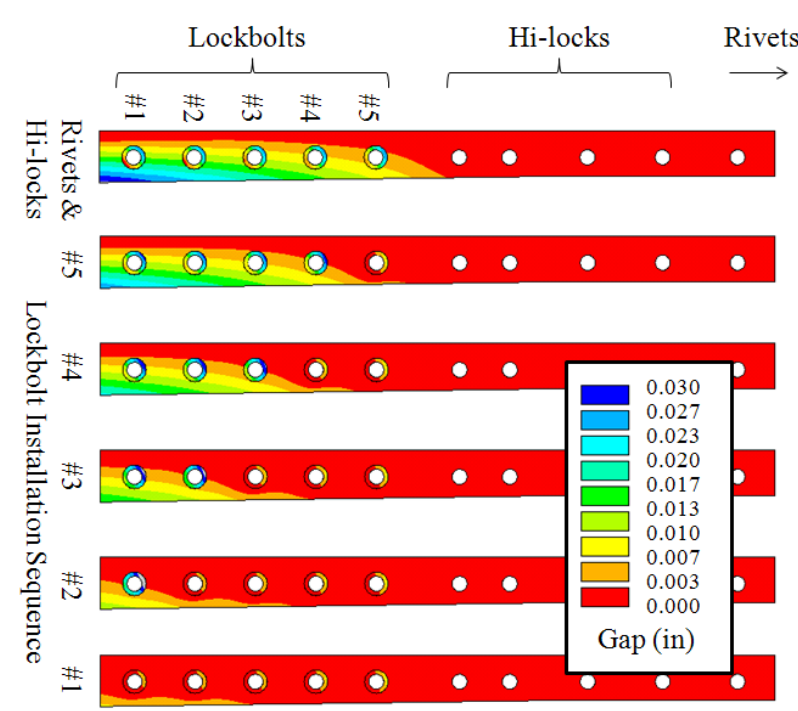

Gap Under Foot

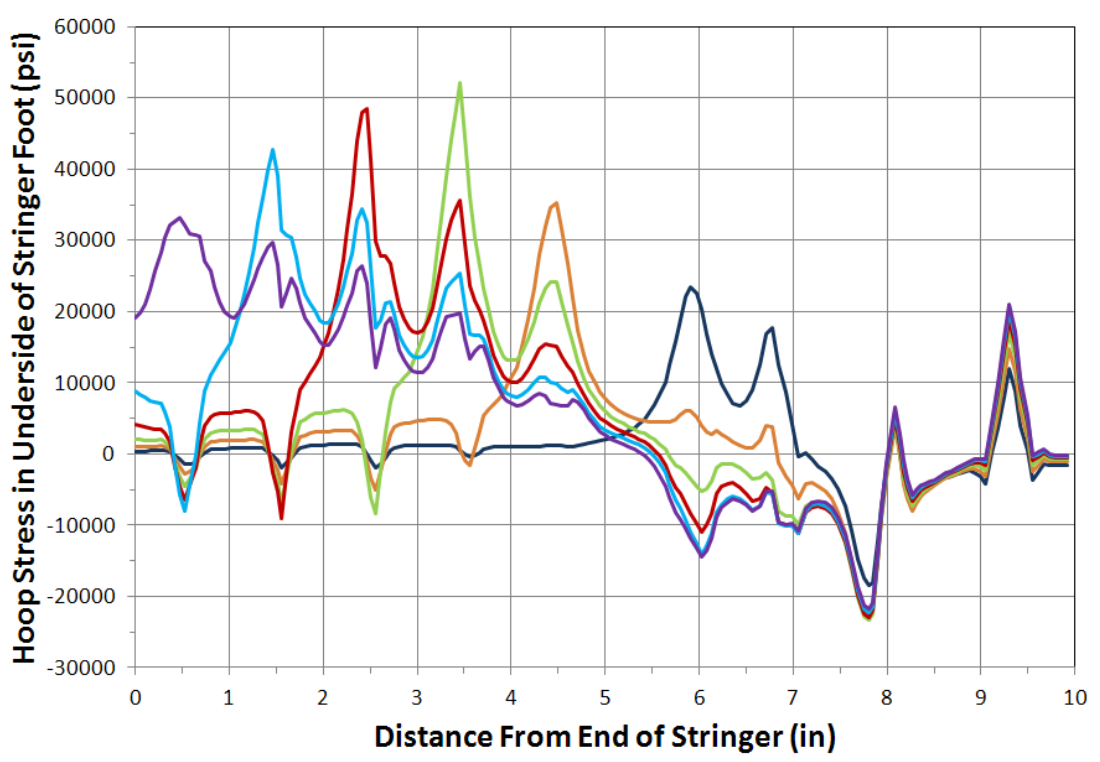

一Rivets \& Hi-locks - Lockbolt\#5 - Lockbolt\#4 一 - Lockbolt\#3 - Lockbolt\#2 -Lockbolt\#1

Assembly stress is significant and it adds directly to bending stress experienced during the chill-down transient. 


\section{Repair Assessment}

\section{Radius Block Repair}

- The radius block was added to the model and the results were compared to the baseline.

- The stringer foot bending directly under the radius block was greatly eliminated.

- The bending stress at the highest stressed region around the fastener \#1 location was also significantly reduced.
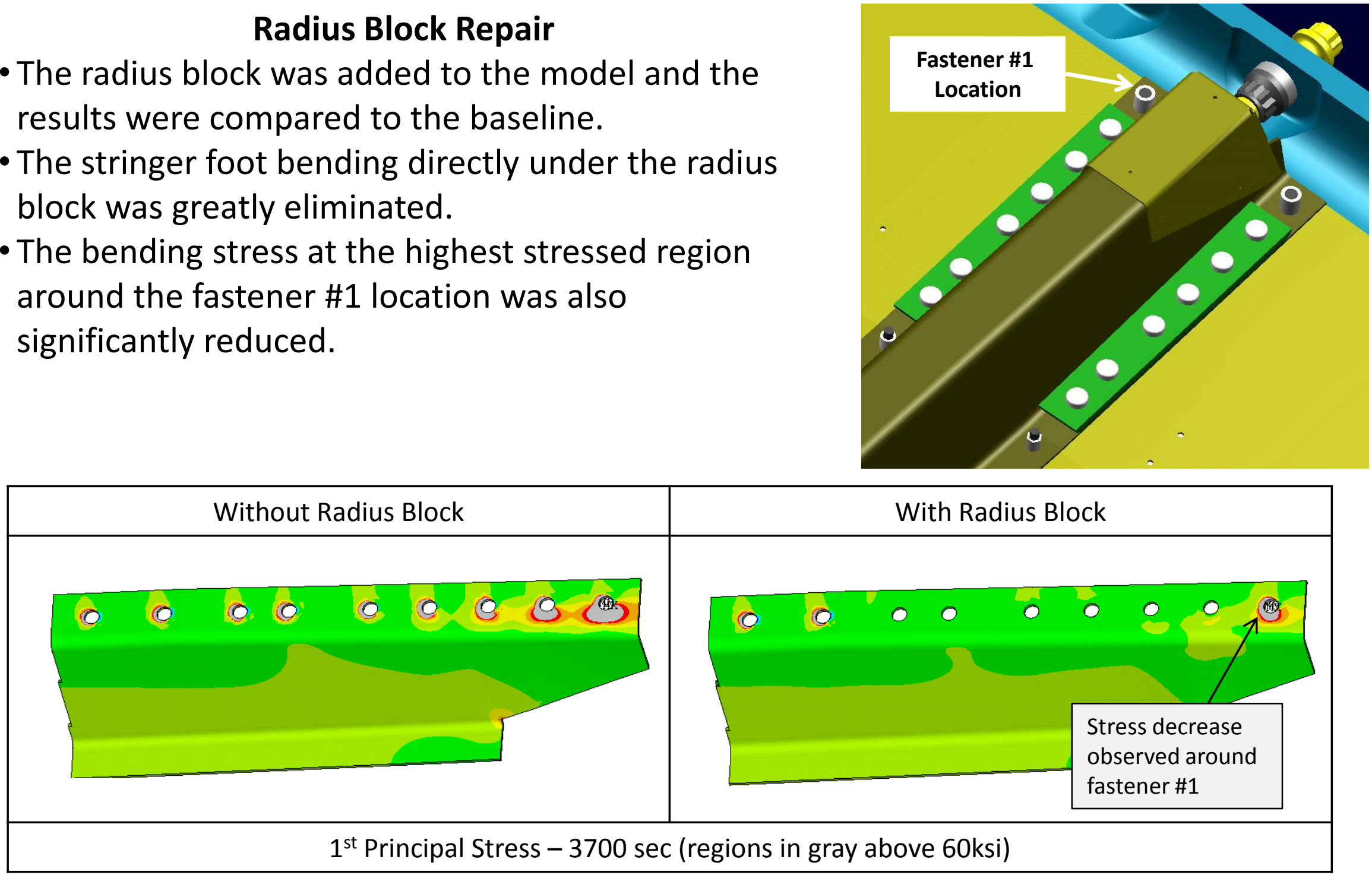


\section{Repair Assessment}

- Load into the stringer is concentrated at the \#2 fastener location.

- Bending stress in the foot is significantly reduced.

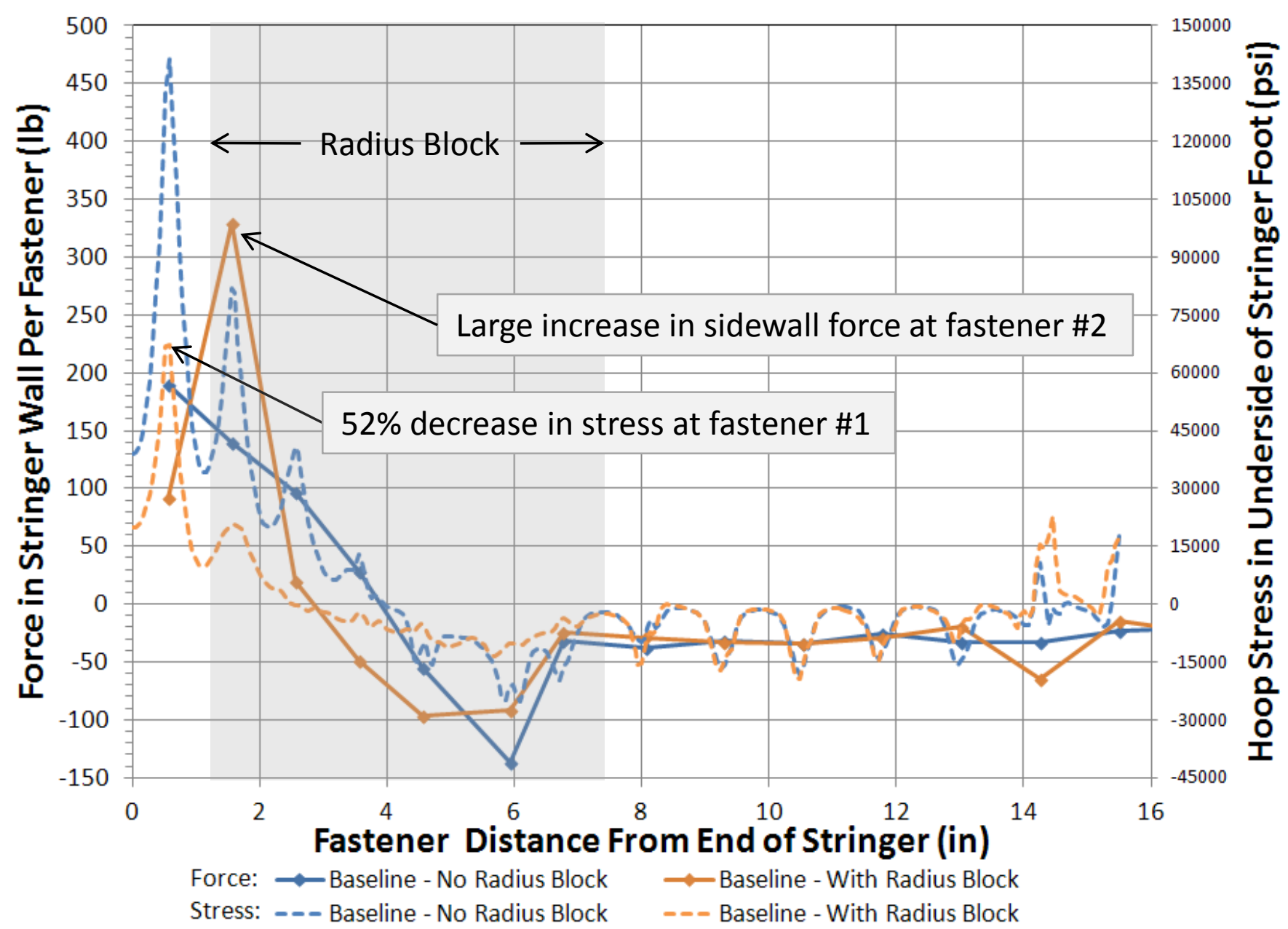




\section{Repair Assessment}

\section{Test Comparison}

- Relative analytical stress/strain compared to relative strength observed in subcomponent testing.

- Comparison is favorable except for test results with two skin doublers.
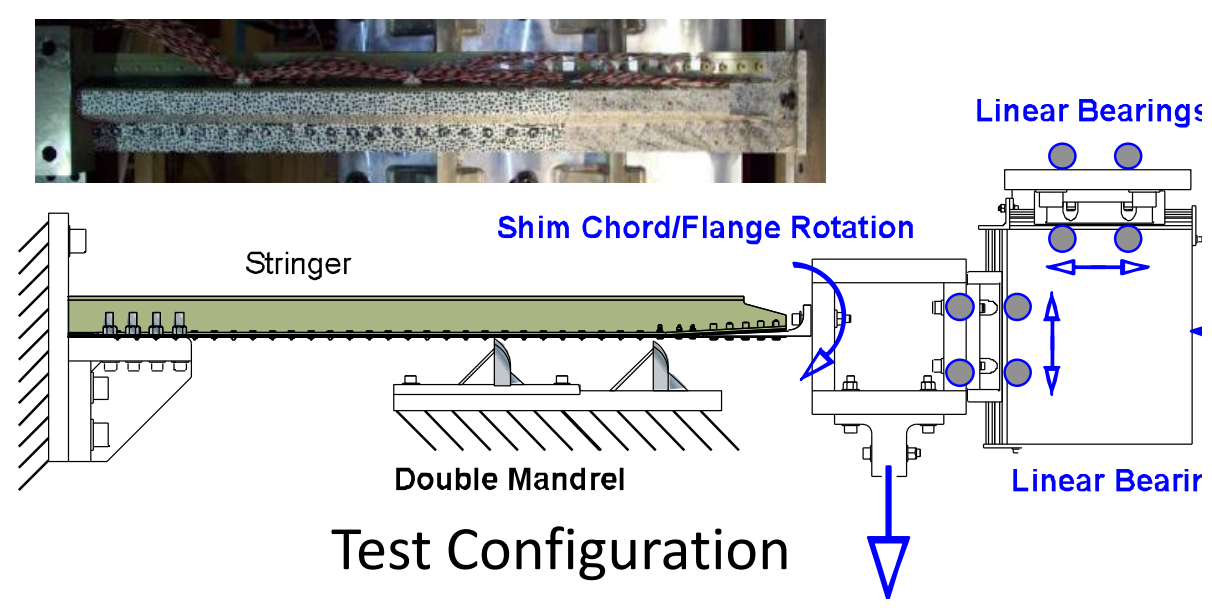

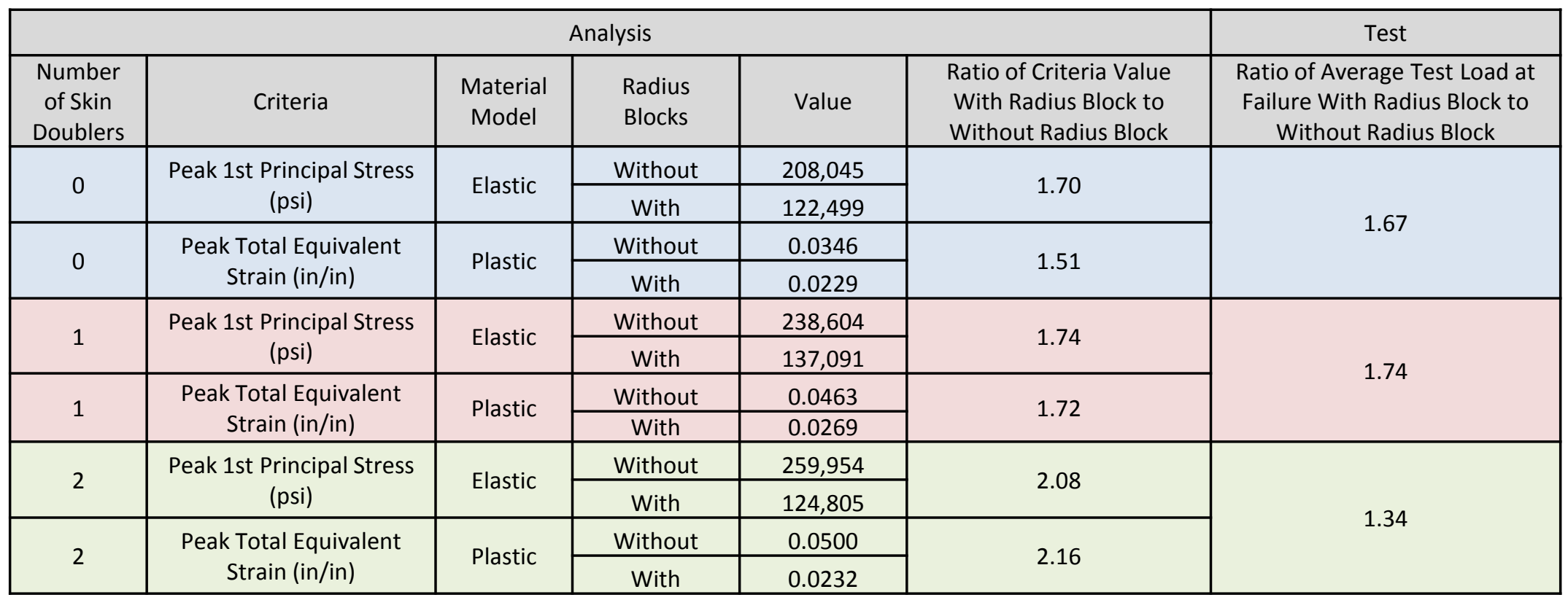




\section{Conclusion}

- The stress analysis of the intertank stringer provided valuable insight into the behavior of the external tank during the tank fill process.

- The results of the analysis compared well to the available test data.

- The analysis provided some qualitative insight into the severity of potential assembly conditions.

- The analysis provided a quantitative estimate of the relative improvement in strength for the redesign.

- Helped support the flight rationale used to attempt another launch. 


\section{Bravo STS-133!}

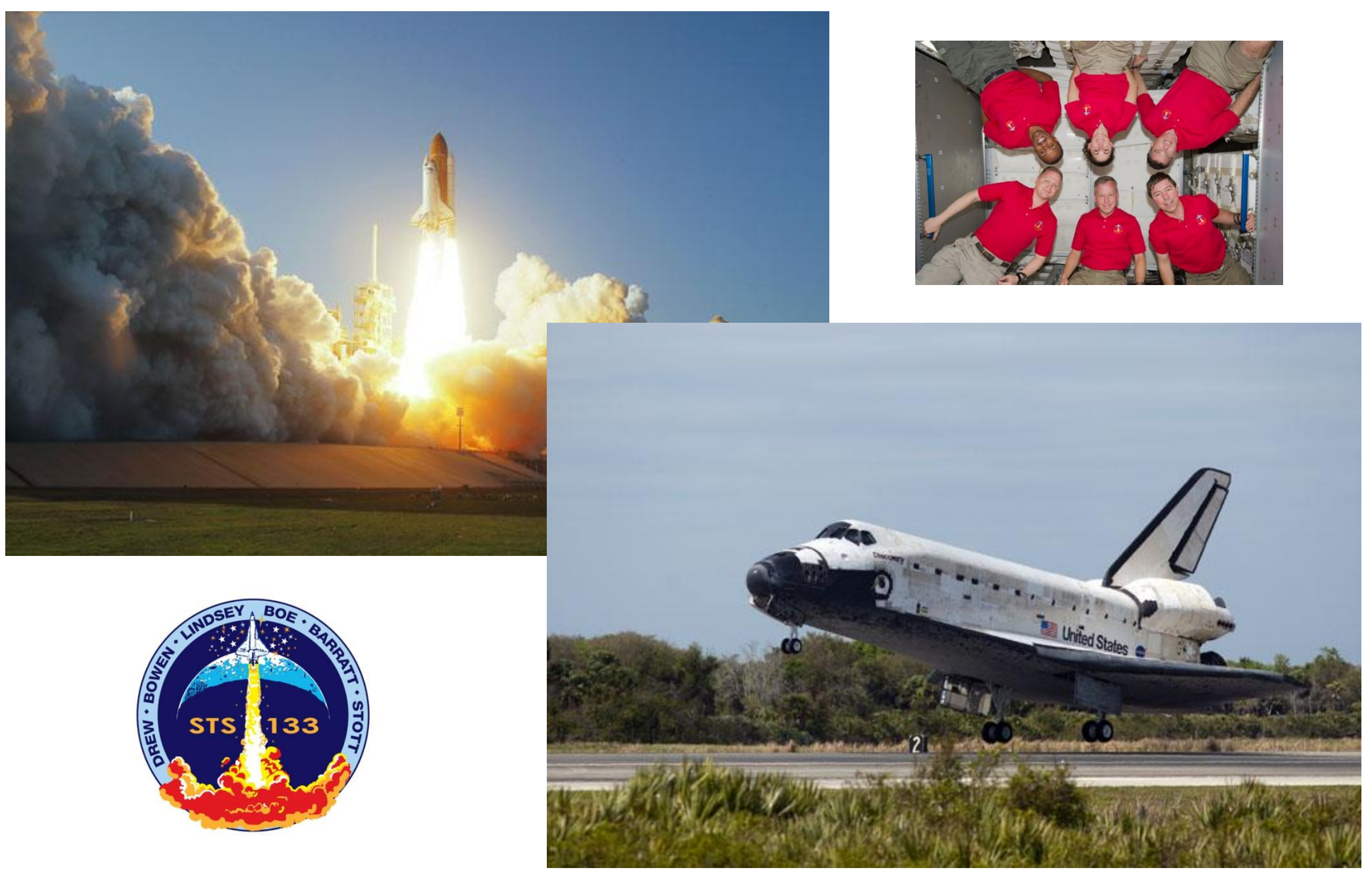

